\title{
Study on Rockburst Nucleation Process of Deep-Buried Tunnels Based on Microseismic Monitoring
}

\author{
Qun Yu, ${ }^{1}$ Chun-An Tang, ${ }^{1}$ Liancong Li, ${ }^{1}$ GuanWen Cheng, ${ }^{1}$ and Lie-Xian Tang ${ }^{2}$ \\ ${ }^{1}$ Institute of Rock Instability and Seismicity Research, Dalian University of Technology, Dalian, Liaoning 116024, China \\ ${ }^{2}$ School of Mining Engineering, University of Science and Technology Liaoning, Anshan, Liaoning 114051, China \\ Correspondence should be addressed to Chun-An Tang; tca@mail.neu.edu.cn
}

Received 6 April 2015; Revised 10 July 2015; Accepted 9 August 2015

Academic Editor: Vadim V. Silberschmidt

Copyright (C) 2015 Qun Yu et al. This is an open access article distributed under the Creative Commons Attribution License, which permits unrestricted use, distribution, and reproduction in any medium, provided the original work is properly cited.

\begin{abstract}
The objective of this study was to investigate the rockburst nucleation process and provide a theoretical basis for its prediction. A microseismic monitoring system was established in deep tunnels at Jinping II Hydropower Station. Using a digital multichannel microseismic monitoring system and monitoring technique, twenty-four-hour continuous real-time monitoring of microseismicity was realized in diversion tunnel \#3. Substantial microseismic monitoring data were acquired to study the macroscopic instability failure mechanisms in the rockburst nucleation process in terms of dynamic crack propagation, including microcrack initiation, development, propagation, shear zone formation, and coalescence. The intrinsic relationship between the spatiotemporal evolution patterns of the microseismicity and the rockbursts was preliminarily explored. The monitoring and analysis results indicated that the driving source of certain rockbursts could be expressed as the combined results of the local rockburst energy and the transfer energy; that is, $E_{\text {drive }}=E_{\text {local }}+E_{\text {transfer }}$. Strong rockbursts can induce the recurrence of rockbursts in nearby locations. In addition, a comparative analysis of the formation and failure mode of molds in underground caverns was performed using the finite element analysis program RFPA. Based on this engineering study, we verified the feasibility of applying microseismic monitoring to rockbursts in deep rock tunnels.
\end{abstract}

\section{Introduction}

With gradual implementation of the Chinese Western Development Project, the South-to-North Water Diversion Project and the West-to-East Power Transmission Project have entered a critical stage. In numerous civil engineering projects (e.g., highway traffic, water conservation, and hydropower), an increasing number of deep, long, and large tunnels are under construction, and the effects of the length, depth, width, and grouping of these underground caverns are increasingly evident. The characteristics above have caused numerous deep rock mechanics problems, especially rockbursts. Rockbursts can destroy underground structures, damage production facilities, and seriously threaten personnel safety. Rockbursts have become a major technical bottleneck in the development of deep underground engineering in China $[1,2]$.

Rockbursts are a dynamic instability phenomenon associated with bursting loose, stripping, ejection, and even catapulting of rocks, where these effects are caused by the sudden release of accumulated elastic strain energy from brittle surrounding rocks during the excavation of underground caverns under high stress. A rockburst is a dynamic geologic disaster triggered by progressive rock failure [3]. Nearly 280 years has elapsed since the first recorded rockburst in a British tin mine in south Stafford in 1738 [4]. Rockbursts are common in South Africa, primarily in gold mines. In 1975,680 rockburst events occurred in 31 gold mines in South Africa, resulting in a death toll of 73 and the loss of 4800 production shifts. On November 28, 2009, an extremely strong rockburst occurred suddenly in a construction drainage tunnel at Jinping II Hydropower Station in Sichuan Province, China (the rockburst is shown in Figure 1). Over $28 \mathrm{~m}$ of the tunnel support systems was completely damaged, the deepest crater caused by the rockburst was nine meters deep, and the total collapse area exceeded $400 \mathrm{~m}^{3}$. Additionally, a tunnel boring machine (TBM) worth 120 million yuan was permanently buried, and construction was stopped. More 


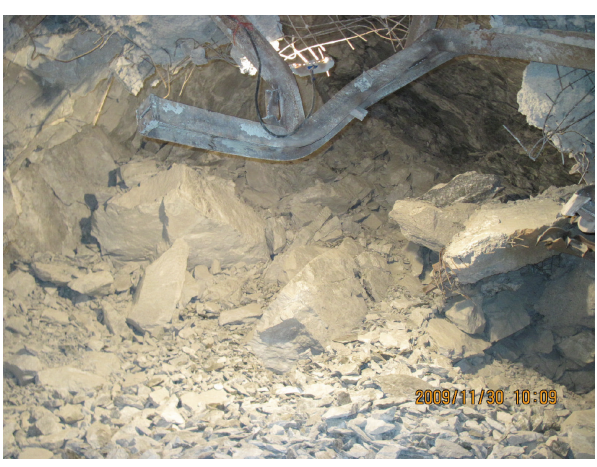

(a)

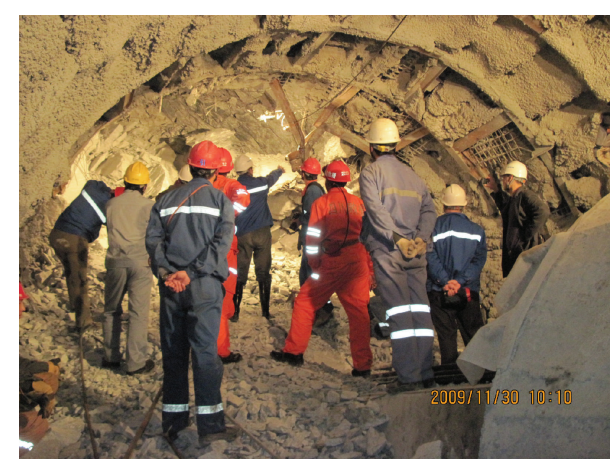

(b)

FIGURE 1: On-site photos showing strong rockburst failure in drainage tunnel at Jinping II Hydropower Station, Sichuan, China (November 28,2009 ). (a) The support systems were seriously damaged and a large area of rocks burst and collapsed. (b) Experts investigated the accident scene after the strong rockburst.

unfortunately, this rockburst resulted in seven dead workers and one injured.

The mechanisms by which rockbursts occur are sufficiently complex that it is even difficult to reach a consensus on the definition of a rockburst [6]. Numerous basic and experimental studies of rockburst have been conducted worldwide based on strength theory [7], stiffness theory [8, 9], energy theory [10], impact proneness theory [11], damage theory [12], fracture theory [13], and instability theory [14]. At the same time, many studies involved attempts to monitor and predict rockburst events, including the microgravity method, rheologic method, rebound method, drilling-yield method, and microseismic method [15]. Although all of these methods have been used, none has proved to be adequately reliable. One innovative idea is to combine comprehensive criteria and classification studies with experimental, simulated, and microseismic monitoring. This is expected to be tested in practice. Therefore, monitoring and predicting rockburst disasters has been one of the most urgently pursued topics in underground engineering in recent years. A successful and mature monitoring system for rockburst prediction has not yet been developed [16].

Long-term research has shown that shear failure is the primary mechanism responsible for rockbursts, as is the case in earthquakes. Rockbursts also exhibit scale invariance. In other words, there is no systematic difference between the physical nature of rockbursts and earthquakes. With the development of geophysics and quantitative seismology, microseismic monitoring information has been used to study rockburst mechanisms and predict rockbursts. Several innovative studies have been conducted overseas using theories from microseismic monitoring methods. In a review of mining-induced microseismicity, Gibowicz [17] introduced research advances in microseismicity resulting from mining, including improvements in microseismic monitoring systems, insight into microseismicity-inducing mechanisms, and the possibility of prediction, prevention, and control of microseismicity. Srinivasan et al. [18] used microseismic events, microseismic energy, and the dominant event frequency as short-term predictors of rockbursts using microseismic monitoring techniques in the Kolar gold mine in India. Based on solid strength kinetic theory and the stiffness inclusion model, Mansurov [19] analyzed changes in relevant parameters of the rock mass that preceded rockbursts in the bauxite deposits in the North Urals Bauxite Mine, and such changes were used to study patterns of variations in microseismicity preceding rockbursts and to conduct rockburst prediction and forecasting. Based on a case study in the Lockerby Mine, Mercer [20, 21] used microseismic monitoring, stress field testing, and simulation calculations to statistically analyze microseismic and stress variables and then obtained a reasonable correlation between these variables. In China, Xie and Pariseau [22] studied the spatiotemporal distribution of microseismicity using fracture theory and damage mechanics. Microseismic events were observed to exhibit a fractal spatial structure. The fractal dimension reflects, to some extent, the stage to which changes in microseismicity have progressed and can thus serve as an indicator for rockburst prediction. Tang [23] developed a seismogenic nucleation model and used the South African microseismic monitoring system ISSI to investigate the spatiotemporal patterns of mine seismicity and their corresponding relationship to mining activity. The relative changes in seismic stress and seismic displacement were used as important evaluation criteria for earthquake preparation and nucleation. The resulting model was applied successfully to rockburst prediction at the Dongguashan copper mine. Zhao et al. [24] studied the microseismicity in a potential rockburst zone during deep excavation in the Hongtoushan copper mine using a microseismic monitoring system. A nonlinear time series analysis of continuously monitored microseismic events was performed, and a potential rockburst was predicted based on the number of microseismic events that occurred per unit of time.

There are two limitations in the aforementioned studies of the nucleation process and precursory characteristics of rockbursts. (1) The traditional methods that have been used primarily include theoretical analysis (strength theory, energy theory, stiffness and buckling theory, etc.), conceptual models, and multiple discrimination formula (Hoke criterion, 
TABLE 1: Strata physical and mechanical properties for the Jinping project.

\begin{tabular}{lcccccc}
\hline & $\begin{array}{c}\text { Elastic } \\
\text { modulus/Gpa }\end{array}$ & $\begin{array}{c}\text { Poisson } \\
\text { ratio }\end{array}$ & Friction angle $/^{\circ}$ & Cohesion/MPa & $\begin{array}{c}\text { Weight } \\
t / \mathrm{m}^{3}\end{array}$ & $\begin{array}{c}\text { Uniaxial compressive } \\
\text { strength/MPa }\end{array}$ \\
\hline $\begin{array}{l}T_{2 b} \text { Baishan group } \\
\text { marble }\end{array}$ & 18.9 & 0.23 & 25.8 & 15.6 & 27.5 & 86 \\
\hline $\begin{array}{l}T_{2 y} \text { Yantang group } \\
\text { marble }\end{array}$ & 17.0 & 0.22 & 26.7 & 13.2 & 27.1 & 70 \\
\hline $\begin{array}{l}T_{3} \text { Sandstone and } \\
\text { slate in upper } \\
\text { Triassic }\end{array}$ & 12.0 & 0.30 & 25.9 & 10.1 & 27.4 & 114 \\
\hline $\begin{array}{l}T_{1} \text { Chlorite schist } \\
\begin{array}{l}T_{2 z} \text { Zagunao group } \\
\text { marble }\end{array}\end{array}$ & 6.53 & 0.32 & 36.0 & 2.6 & 27.2 & 79 \\
\hline
\end{tabular}

Turchaninov criterion, Russenes criterion, etc.). Those methods can only make criterion to rockburst risk on the basis of static quantitative calculation results. However, the essence of rockburst nucleation and development process is a dynamic damage process in terms of microcrack initiation, development, propagation, and macroscopic failure. If a study is based only on the results of static calculations, it is difficult to conduct a reasonable evaluation of the risk of rockbursts; therefore, there are limitations. Dynamic and quantitative monitoring analysis of rockburst evolution can better reflect dynamic instability failure in an actual rockburst event. (2) Previous studies have primarily focused on rockbursts or pressure bumps in metal and coal mines. Thus far, few studies and reports of rockbursts in deep tunnels have been published.

To address these issues, our study was conducted using engineering practices in the deep diversion tunnel at the Jinping II Hydropower Station. Substantial microseismic monitoring data were obtained from a digital multichannel microseismic monitoring system. The mechanisms of rockburst nucleation and development were investigated in terms of dynamic crack propagation by considering microcrack initiation, development, coalescence, and instability failure during rock damage in underground caverns. The intrinsic relation between rockbursts and the spatiotemporal evolution patterns of the microseismicity during instability failure of the underground surrounding rocks was explored. The results are a preliminary demonstration of the feasibility of using a microseismic monitoring system for real-time monitoring and prediction of rockbursts in deep rock tunnels. A novel research tool has also been developed for late-stage excavation and safety management of underground caverns.

\section{Brief Introduction of Jinping II Hydropower Station Project}

2.1. Overview. The Jinping II Hydropower Station is located in the Jinping River Bend on the main stream of the Yalong River, which is located at the junction of three counties (Muli, Yanyuan, and Mianning) in the Liangshan Yi Autonomous Prefecture, Sichuan, China. Jinping II exploits the natural elevation drop at the Jinping Bend of the Yalong River by cutting across the Bend and using straight diversion tunnels to divide the water and generate power. Jinping II is an important cascade hydropower station on the main stream of the Yalong River, with a total installed capacity of $4800 \mathrm{MW}$ and a unit capacity of $600 \mathrm{MW}$. The hydropower station is composed of seven parallel tunnels (shown in Figure 2): diversion tunnels \#1-4, one construction drainage tunnel, and auxiliary traffic tunnels $\mathrm{A}$ and $\mathrm{B}$. The diversion tunnel line is approximately $16.67 \mathrm{~km}$ long and is at a typical depth of $1500-2000 \mathrm{~m}$, with a maximum depth of $2525 \mathrm{~m}$. Of the total length of the tunnels, 75.8 percent is at depths exceeding $1500 \mathrm{~m}$. Two of the diversion tunnels (\#1 and \#3) and the drainage tunnel were constructed by TBM tunneling, and the excavation sections were $12.43 \mathrm{~m}$ and $7.2 \mathrm{~m}$ in diameter, respectively. The other two diversion tunnels ( $\# 2$ and \#4) were constructed by drilling and blasting, and the largest excavation section was a $13 \mathrm{~m}$ horseshoe-shaped tunnel.

2.2. Geological Settings. Jinping II is located in a topographic slope border region of the Qinghai-Tibet Plateau and the Sichuan Basin. The fault systems can be classified in terms of their structural features, distribution, and orientation into four groups: NNE, NNW, NE-NEE, and NW-NWW. All four groups of faults tend to dip steeply. Among these four groups, the NNE and nearly EW (NWW and NEE) trending tensile-shear joints are well developed. The primary axis of the tunnel has an azimuth of $\mathrm{N} 58^{\circ} \mathrm{W}$. The strata that the headrace tunnels pass through are all Triassic strata, namely, Triassic $\left(T_{1}\right)$, Yantang group marble $\left(T_{2 y}\right)$, Baishan group marble $\left(T_{2 b}\right)$, Zagunao group marble $\left(T_{2 z}\right)$, and Sandstone and slate in upper Triassic $\left(T_{3}\right)$. The physical and mechanical properties of the strata are listed in Table 1. The rocks are hard, brittle, complete, and dense, exhibit high self-sustained carrying capacity, and provide good cavitation conditions. The maximum, intermediate, and minimum principal stresses all increase with depth. The maximum principal stress is nearly $70 \mathrm{MPa}$ in the direction of $S 18-54^{\circ} \mathrm{E}$ and at a dip of $24-73^{\circ}$. This maximum first-principal stress is likely located at a depth of $9 \mathrm{~km}$ at the western end of the diversion tunnel, which is at the greatest depth along the vertical section of the tunnel. The engineering geological profile and the surrounding rock classification are shown in Figure 3. 


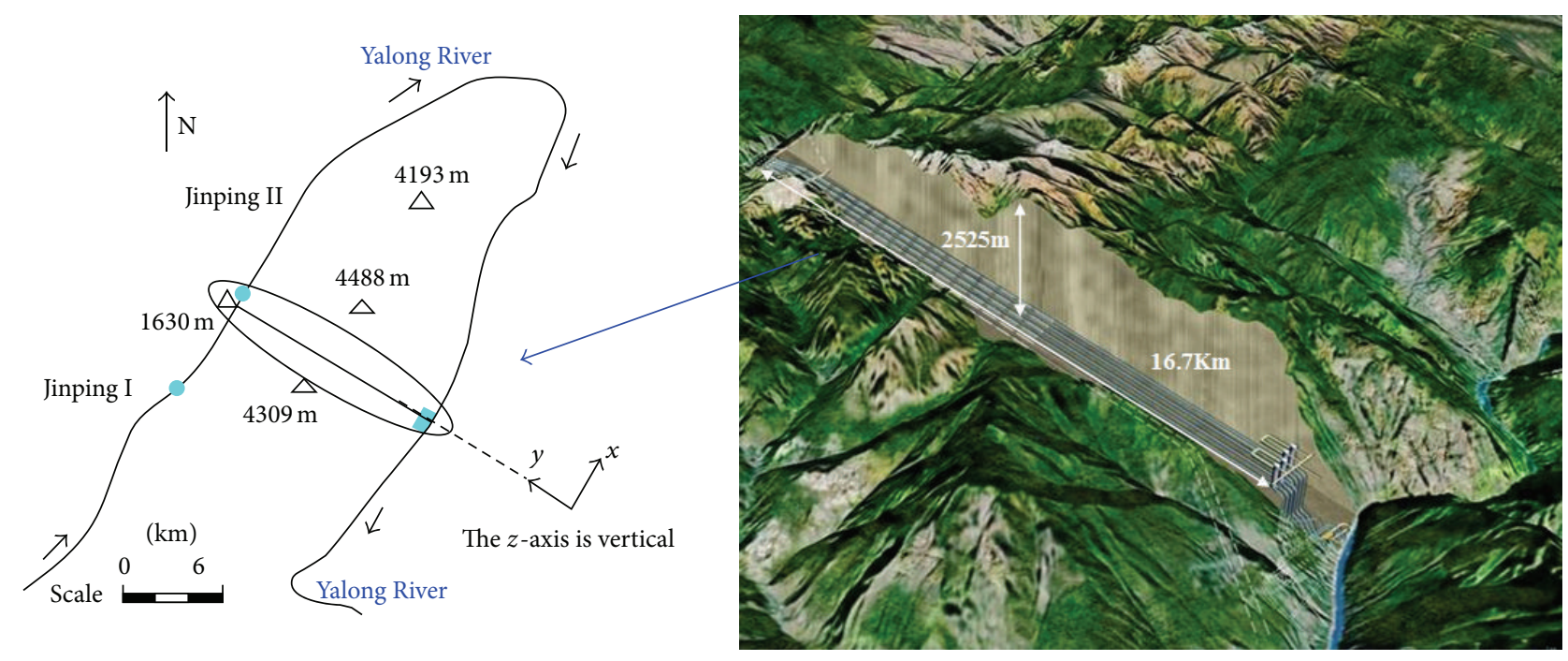

(a)

(b)

Headrace tunnels

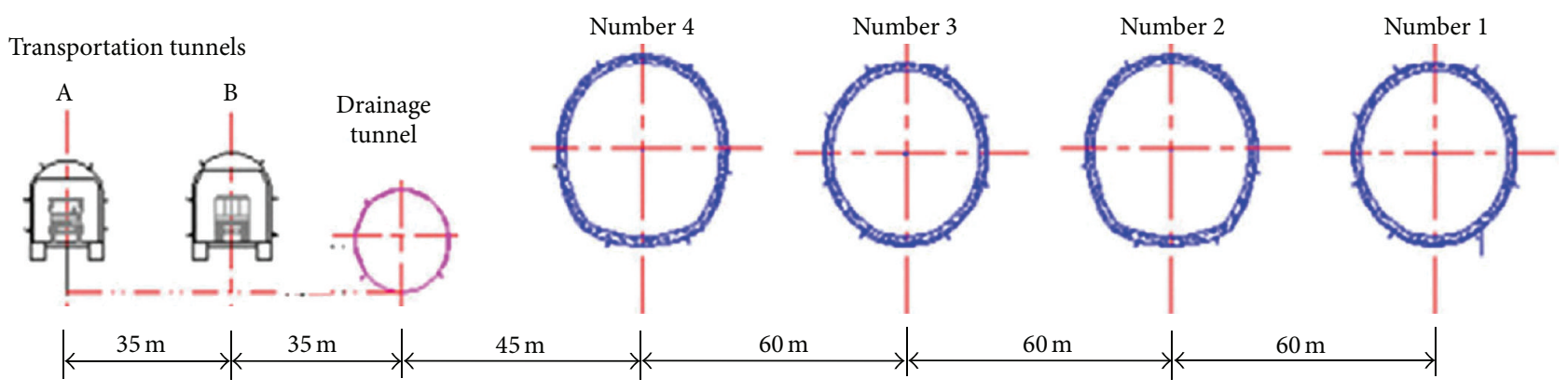

(c)

FIGURE 2: Overview of the Jinping II Hydropower Station. (a) Layout of the Jinping hydropower project across the Yalong River; (b) location of the Jinping II Hydropower Station; and (c) configuration of seven tunnels [5].

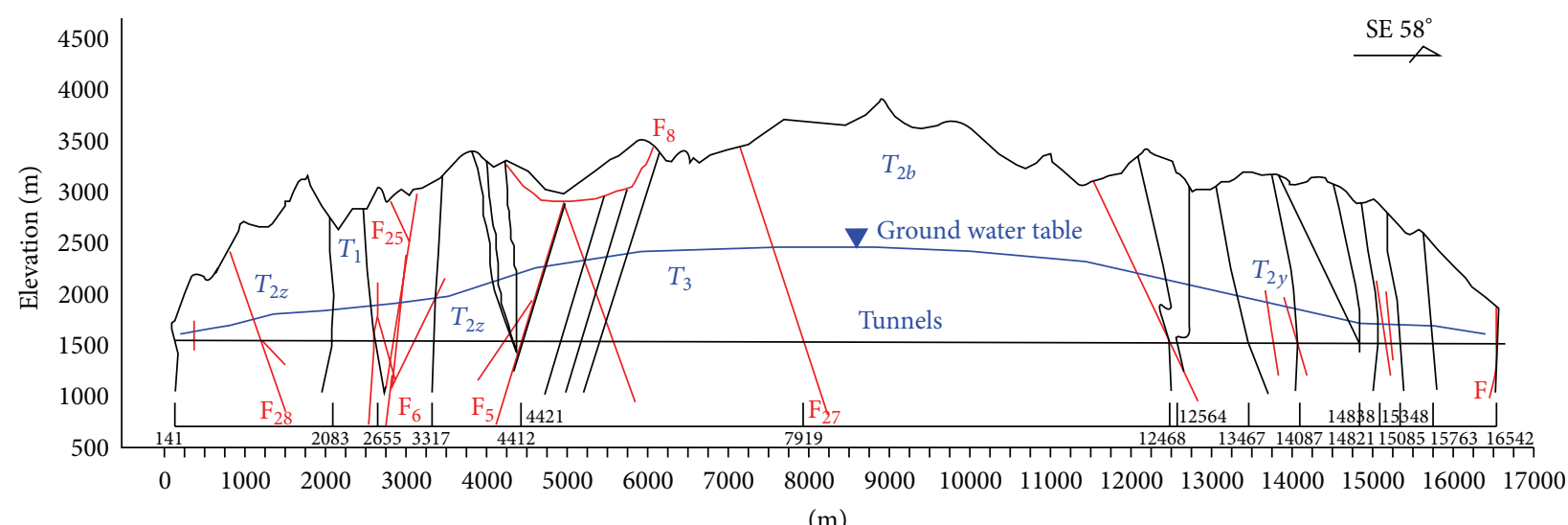
$T_{2 z}$ Zagunao group marble
$T_{1}$ Chlorite schist
$T_{2 b}$ Baishan group marble
$T_{2 y}$ Yantang group marble
$T_{3}$ Sandstone and slate in upper Triassic
Fault

FIGURE 3: Geological profile along the tunnel alignment. 
2.3. Microseismic Monitoring System and Monitoring Methods. Microseismic monitoring is an advanced spatial threedimensional rock microcrack monitoring technology developed in recent years that has been rapidly developed and widely applied to deep underground engineering in several countries, including Canada, Australia, South Africa, the United States, and Japan [25-29]. Microseismic monitoring has become an important tool in dynamic geologic disaster monitoring and safety management [30]. Microseismic monitoring is a geophysical method that is used to monitor the development and location of microcracks that are generated during rock deformation and failure. When external disturbances induce cracks in the rock, the accumulated internal strain energy is released in the form of elastic waves that produce microseismic events (MS events). Microseismic monitoring has been extensively used in a wide range of fields, such as mining engineering [31], underground oil and gas material storage [32], slope engineering [33], and hot dry rock power generation [34].

The Jinping II Diversion Tunnel Monitoring Project was implemented using a microseismic monitoring system that was manufactured by ESG (Engineering Solutions Group, Canada). The monitoring system consisted of the following primary components: Paladin digital signal acquisition system, Hyperion digital signal processing system, acceleration sensors, a data communication modem, electrical and optical cables, and MMS-view visualization software based on remote transmission by a wireless network (Figure 4).

Based on the geologic-geomorphologic characteristics of the deep diversion tunnels and the features of the tunnel sections in Jinping II, six-channel data loggers were arranged at the rear of the working face of diversion tunnel \#3. This configuration facilitated continuous real-time monitoring of the microcracking activities that were generated during rock unloading and multiple aspects of source information regarding massive microseismic events were acquired (e.g., spatiotemporal data, error, magnitude, and energy). The system filtered the acquired data and provided complete waveform and spectral analysis diagrams. The system automatically identified the type of microseismic events and eliminated noise events using technologies such as threshold setting and broadband detection. Details of the microseismic monitoring and analysis system are shown in Figure 5. The acceleration sensors were installed in an array at the spandrels of the north and south walls. First, two sensors were placed $25 \mathrm{~m}$ apart at a distance of approximately $50 \mathrm{~m}$ from the rear of the working face. When the TBM advanced approximately $25 \mathrm{~m}$, the two sensors in the rear of the working face were moved forward to a location approximately $50 \mathrm{~m}$ from the working face. This process was repeated such that the microseismic monitoring system closely followed the working face. Thus, the data acquisition was coordinated with the TBM motion, and continuous real-time monitoring was achieved.

2.4. Monitoring Range Selection. In diversion tunnel \#3, the section from K8 + 000 to $\mathrm{K} 11+000$ is $1900-2525 \mathrm{~m}$ deep (the maximum depth of the entire tunnel section is $2525 \mathrm{~m}$ ), which is classified as a great depth zone. The maximum, intermediate, and minimum principal stresses increase with depth. The engineering geological profile is shown in Figure 6. In the project area, karst and groundwater are poorly developed. Lithologically, the formation is primarily composed of $T_{2 b}$ gray-grayish white, dense, and thickly bedded crystalline limestone and marble. The surrounding rocks are mainly dominated by class II-III rocks, which are thickly bedded and exhibit good integrity due to their stiffness and brittleness. In the monitoring areas, the stress is mainly from the gravity field, the maximum principal stress exceeds $65 \mathrm{MPa}$, and thus this zone is classified as a high-stress zone. The measured rockburst proneness index $W_{e t}$ ranges from 1.32 to 5.8: thus, the rock mass contains high energy along the tunnel axis, which is consistent with the strength conditions necessary for high-stress failure. Therefore, it is not only fundamentally interesting but also practically important to perform a comprehensive study of the surrounding rock lithology in combination with the geologic conditions, and the rockburst proneness index was used to select representative areas of frequent microseismicity and strong rockburst proneness as the key point of microseismic monitoring and analysis.

\section{Microseismic Monitoring Results and Analysis during TBM Tunneling in Diversion Tunnel \#3}

3.1. TBM Excavation. Table 2 shows the excavation progress of the TBM from January 20 to March 1, 2011. From late January to February 3 , the TBM was in the excavation stage during which the tunnel was being undercut. Despite the high tunneling speed, preexcavation of the pilot tunnel partially released stress and energy, which substantially reduced the local stress concentration in the rock mass. No rockburst occurred during this period. From February 4 to midFebruary, the TBM excavation entered the full-face excavation stage. Multiple strong rockbursts occurred during this period, which reduced the excavation speed: the tunneling footage was also relatively short. The TBM was affected by rockbursts in mid-February, and operations were halted for personnel and equipment safety. Except for $4 \mathrm{~m}$ of tunneling on February 21, no footage was recorded in late February.

3.2. Spatiotemporal Distribution Characteristics of Microseismicity. Figure 7 presents a projection map of the spatiotemporal (time, location, and moment magnitude) distribution of the microseismicity from January 20 to February 21, 2011. Each ball represents a microseismic event: the size of the ball denotes the energy level, and its color denotes the moment magnitude. The microseismicity distribution from January 20 to February 5, 2011, is shown in Figure 7(a). During this period, the TBM was in the excavation stage where the semiface of the tunnel was being undercut. As the stress and energy had been partially released by the pilot tunnel, this tunnel section was primarily associated with low-energy and small-magnitude microseismic events. The discrete distribution of these microseismic events resulted in a low potential for large-scale rock failure. From February 6 to February 10, the number of microseismic events and the energy release exhibited an increasing trend. The number 


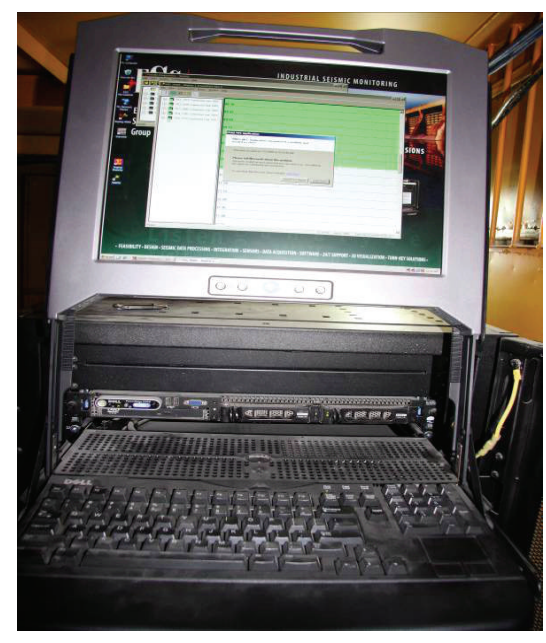

(a)

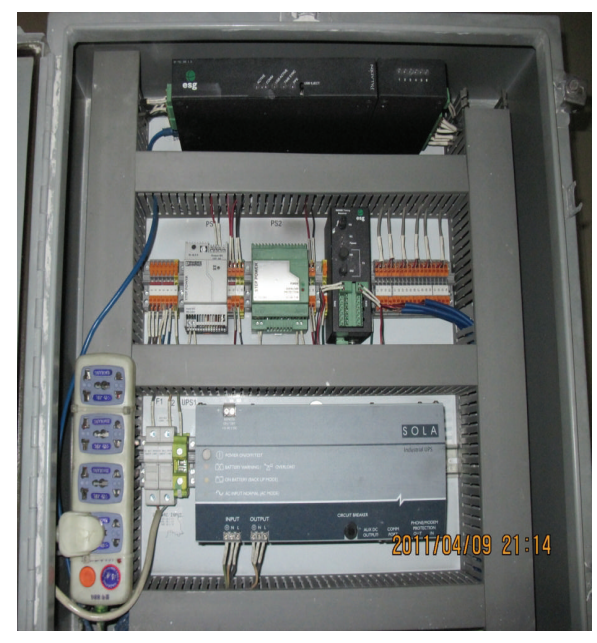

(b)

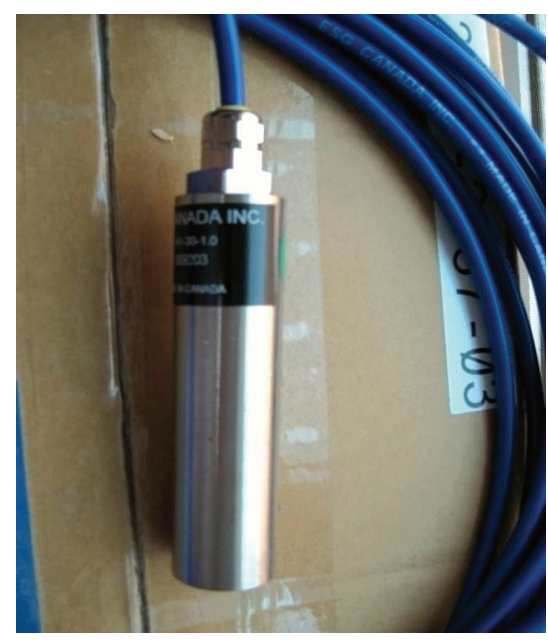

(c)

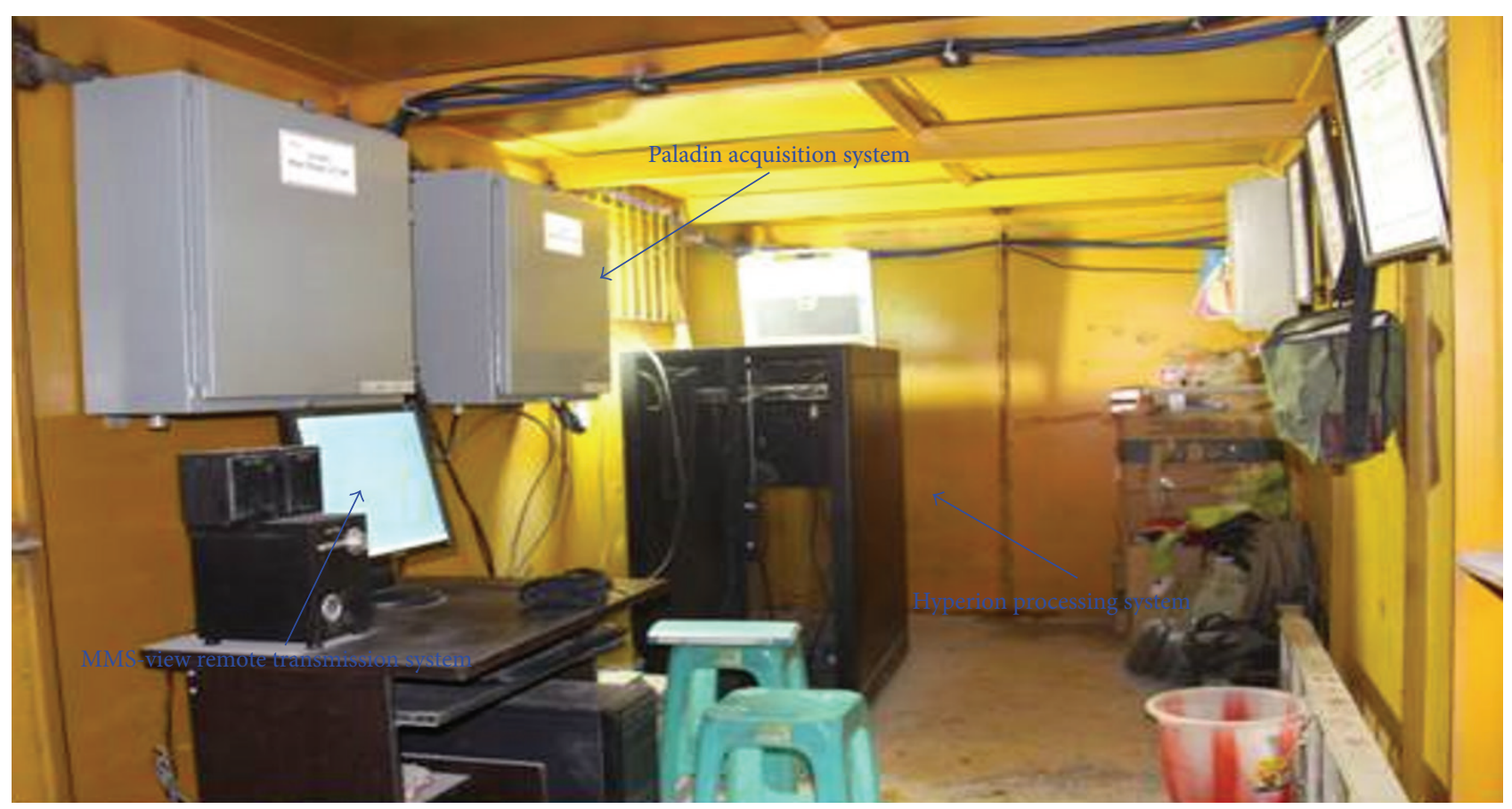

(d)

Figure 4: Constitution of microseismic monitoring system. (a) Hyperion digital signal processing system. (b) Paladin digital signal acquisition system. (c) Acceleration sensor. (d) Center of the site monitoring system.

of events was significantly impacted by the TBM excavation the day before the rockburst (February 11). The number of microseismic events increased to produce a cluster in the north sidewall $25 \mathrm{~m}$ from the rear of the working face. Meanwhile, there was an abnormal energy release from the surrounding rocks (Figure 7(b)) that was significantly higher than the early release and showed clear signs of rockburst. From February 11 to February 16, a cluster of microseismic events was observed in tunnel \#3 from K9 + 629 to K9 + 639 (designated \#3K9 + 629 to K9 + 639), while substantial energy was released from the surrounding rocks (Figure $7(\mathrm{c})$ ). A total of 13 microseismic events occurred on February 16.
These events exhibited a significant level of activity with accelerated clustering. A preliminary analysis indicated that the surrounding rocks began to enter the failure stage after reaching their peak strength, and a rockburst danger zone reappeared. There were few microseismic events from February 17 to February 21; however, the distribution of these events reflected significant clustering, and events with high energy and large magnitude were continuously being generated (Figure $7(\mathrm{~d})$ ). The cumulative energy release from the surrounding rocks was significantly greater than that at the earlier stage and formed a zone of concentrated microseismicity at \#3K9 + 607 to K9 +622 . During this 


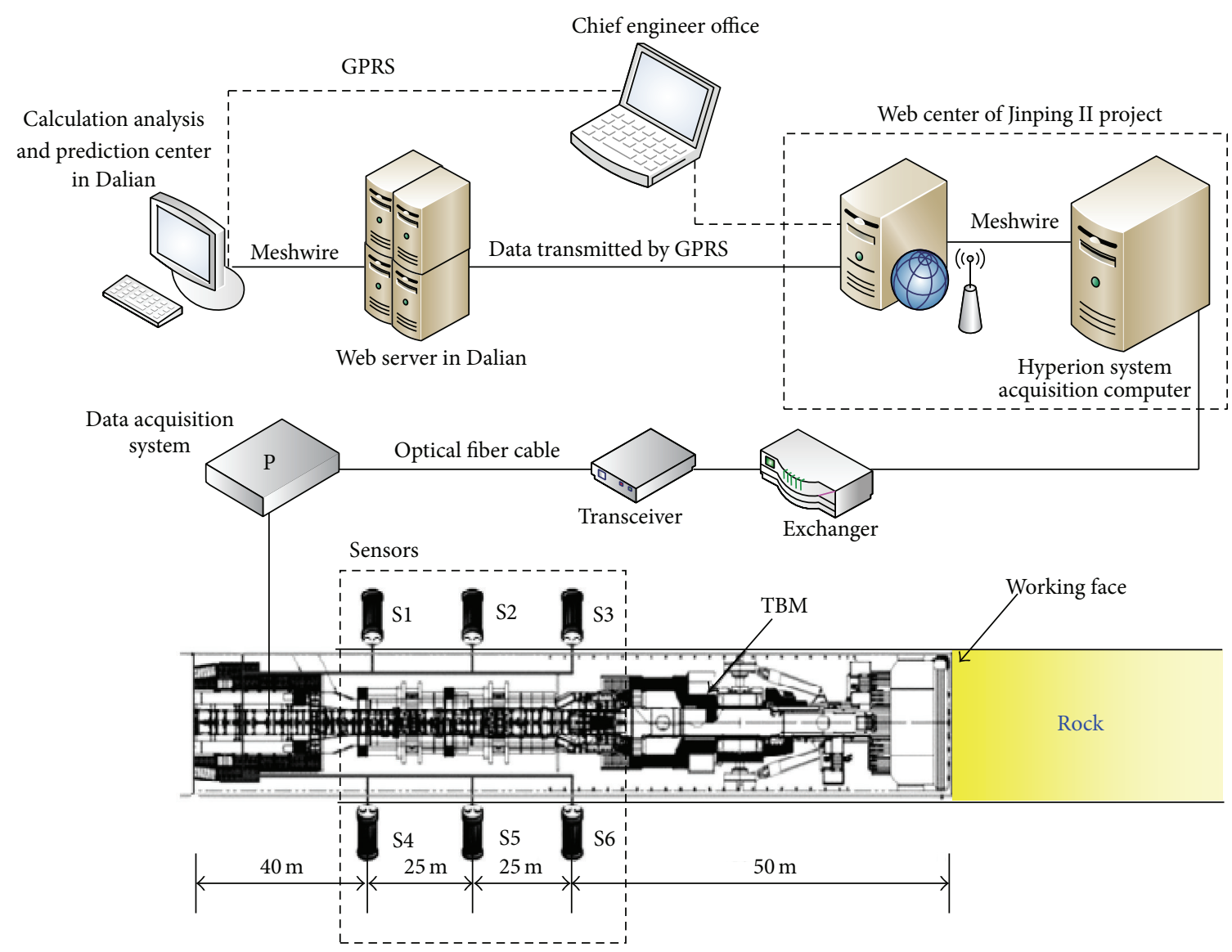

FIGURE 5: The monitoring and analysis system for rockbursts during TBM tunneling for Jinping II Hydropower Station.

period, medium-to-strong rockbursts occurred three times, resulting in landslides in multiple areas at the rear of the working face.

\subsection{Microseismic Energy Dissipation, Energy Density, and Pre-} liminary Delineation of Rockburst Danger Zone. The microseismicity rate and the dissipated energy versus time (January 20 to February 21, 2011) are shown in Figure 8. Before the two strong rockbursts (on February 11 and February 21), there was a significant level of microseismicity, and the energy release from microcracking of the rock masses trended upward. There were sudden and sharp increases in the energy release. There was a significant cumulative energy release from the microseismicity, and there was continuous doubling of the energy release; the one-day peak energy reached $3.72 \times 10^{4} \mathrm{~J}$, particularly before the rockburst on February 21, which was much greater than the normal level of energy release. This phenomenon is a typical microseismic abnormality showing clear signs of a rockburst.

The evolution of the microseismicity energy density in diversion tunnel \#3 is shown in Figure 9, wherein points A, $\mathrm{B}$, and $\mathrm{C}$ correspond to the positions of the rockbursts that occurred in the tunnel section (Figure 9(d)). From January 20 to February 10, 2011, an energy density cloud appeared near point A the day before the rockburst (Figures 9(a) and 9 (b)). Thereafter, the energy density cloud in the rockburst core area also appeared near points $\mathrm{B}$ and $\mathrm{C}$ during the next six days (Figure 9(c)). As the TBM advanced, the number of microseismic events and energy release remained high because of the unloading effect of the excavation and the inherent tendency of the surrounding rocks to undergo stress adjustment. At point $\mathrm{C}$, the density cloud of the rockburst core area displayed more obvious signs of rockburst and was gradually expanding (Figure 9(d)). Multiple rockbursts during the period of February 16 to February 21, 2011, occurred in this core area. Despite the relatively high energy density near point $\mathrm{P}$, there was no rockburst in this region. Thus, point $\mathrm{P}$ could be regarded as a potential rockburst danger zone. The aforementioned analysis indicates that an energy density cloud can be used to qualitatively identify a rockburst nucleation zone and to delineate potential rockburst danger zones, which in turn can be used to analyze the causes and developmental trends of rockbursts.

\section{Characteristics of Microseismicity Evolution during Rockburst Nucleation Process}

Originally, the microseismic energy dissipation, the cumulative number of MS events, and the event density indirectly reflect the extent of damage to the rock from microcracks. These are the most basic parameters and are able to reveal the characteristic of microfracturing and instability involved 


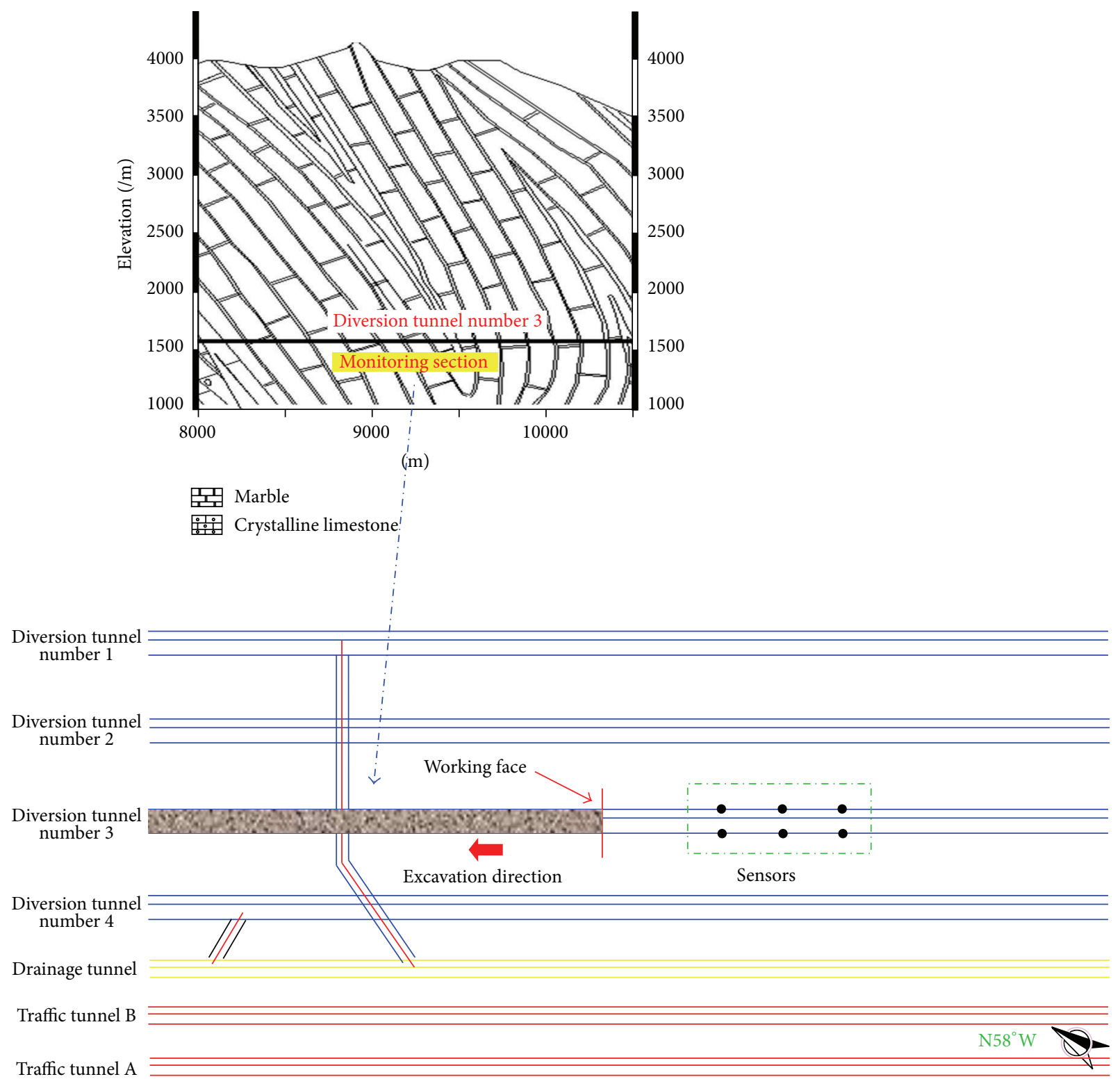

FIgURE 6: Geological profile of microseismic monitoring area in diversion tunnel \#3 of the Jinping II Hydropower Station.

in the rockburst nucleation process. Each microseismic event represents one microcrack. Greater densities of microseismic events in space are indicative of greater microcrack clustering within the rock. A higher local stress concentration increases the potential for microcracks in the interior of the rocks to propagate and coalesce into a crack zone. The local strength of the rock mass then decreases further, and a rockburst is more likely to occur.

Figure 10 shows the microseismicity distribution and the evolution characteristics of the rockburst nucleation process during TBM tunneling in diversion tunnel \#3 (January 20 to March 1, 2011). Details of rockbursts that occurred during this period are shown in Table 3. Generally speaking, there were primarily two zones of relatively concentrated microseismicity, which corresponded to the tunnel sections of $\# 3 \mathrm{~K} 9+640$ to $\mathrm{K} 9+662$ and $\# 3 \mathrm{~K} 9+607$ to $\mathrm{K} 9+637 . \mathrm{A}$ preliminary on-site analysis indicated that the surrounding rocks were greatly affected by the TBM tunneling speed on February 10, resulting in underground stress redistribution and transfer. As a result, the rock cracks propagated deeper into the rock (upper left in Figure 10), producing a "banded" distribution of concentrated microseismicity, which is designated shear zone I and is denoted by a blue oval. When the cracks had propagated to the extent necessary to form a shear zone and coalesced, a strong rockburst occurred on February 11. Along with the progress of excavation, stress was continuously transferred and accumulated. The increase in the number of microseismic events resulted in the formation of a second concentrated microseismicity area, zone II. Within zone II, high energy, large magnitude events 


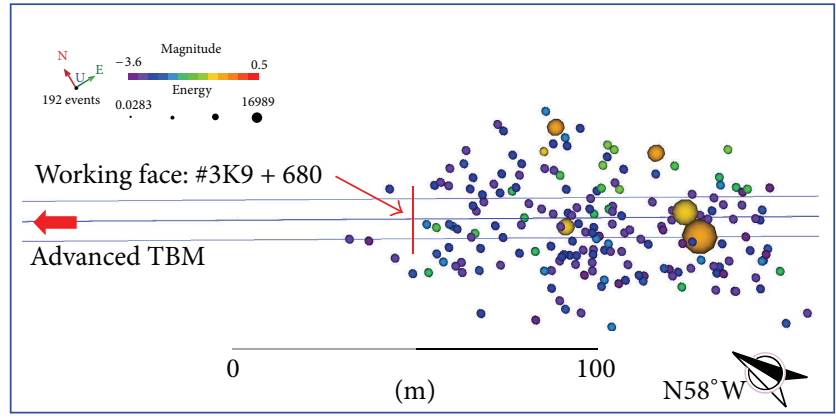

(a)



(c)

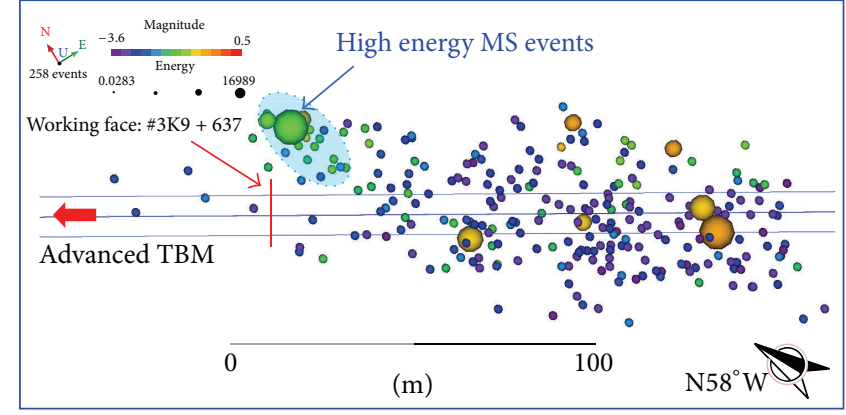

(b)

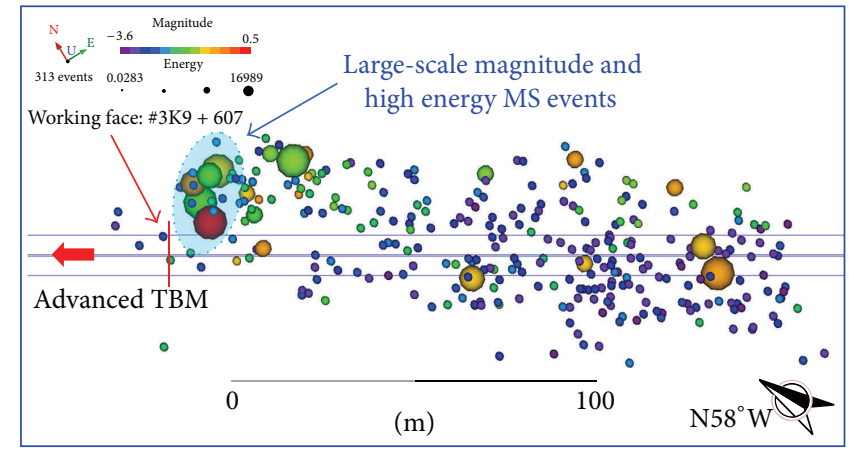

(d)

FIGURE 7: A projection map of the spatiotemporal distribution of microseismicity during TBM tunneling in diversion tunnel \#3 (January 20 to February 21, 2011). (a) Microseismicity distribution from January 20 to February 5, 2011; (b) microseismicity distribution from January 20 to February 10, 2011; (c) microseismicity distribution from January 20 to February 16, 2011; and (d) microseismicity distribution from January 20 to February 21, 2011.

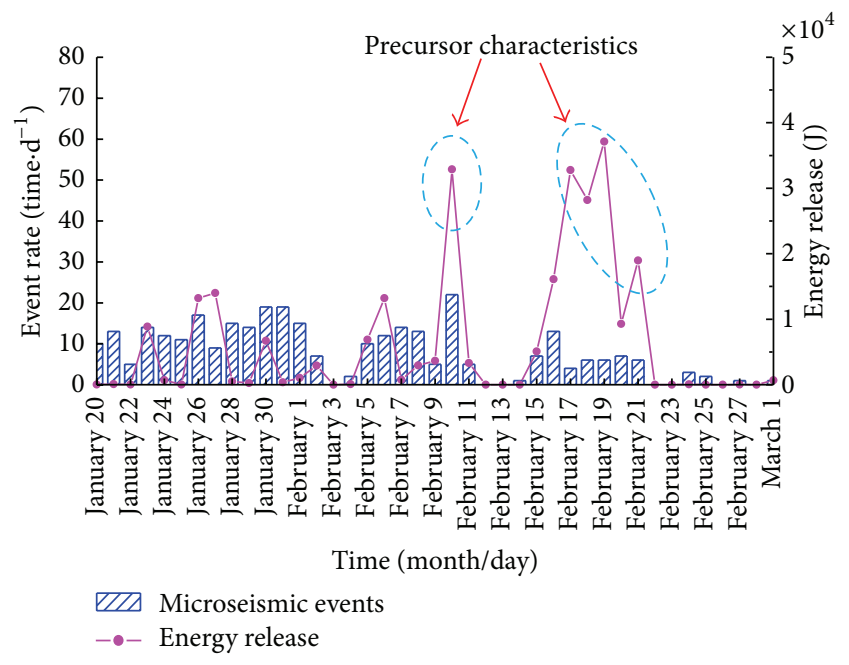

FIGURE 8: Correlation chart between energy release of microseismic events and activity rate and time (January 20 to March 1, 2011).

continued to occur, resulting in more severe rock damage. The interior microcracks tented to propagate, forming a new shear zone (shear zone II is denoted by a pink oval). The unloading effect of the TBM excavation and multiple rockburst accidents within several days caused cracks to propagate continuously, while the stress was accumulated and transferred. The two concentrated microseismicity zones (zones I and II) were close to each other such that multiple factors combined to seriously deteriorate the rock mechanical properties. Small cracks initiated, propagated, connected, and coalesced to form large cracks. The spatial distribution of the microcracks evolved from a disordered scattered pattern into an ordered concentrated self-organized pattern, which ultimately resulted in the coalescing of the crack zones between the two zones of concentrated microseismicity. The resultant shear zone was surrounded by the free face of the tunnel, forming a triangular area in which the rock stress and energy were transferred and released toward the free face and the surrounding areas. When the peak strength of the rock was reached, instability failure of the rock occurred by stripping of substantial spall from the rock and the ejection of rock wedges. Eventually, rockbursts occurred via tensile (and compressive) shear failure over large areas on February 21. There were errors in the source positioning of the microseismic events; thus, only approximate locations of microcracking events could be determined. The microcrack formation process is shown in Figure 10.

The rockburst failure in the TBM tunneled section is shown in Figure 11. The rock mass was macroscopically intact and exhibited fresh crack surfaces. There were typical burst blocks of wedge shapes, and spalling was observed. The dimensions of the largest burst blocks were $1.2 \mathrm{~m} \times 1.0 \mathrm{~m} \times$ 


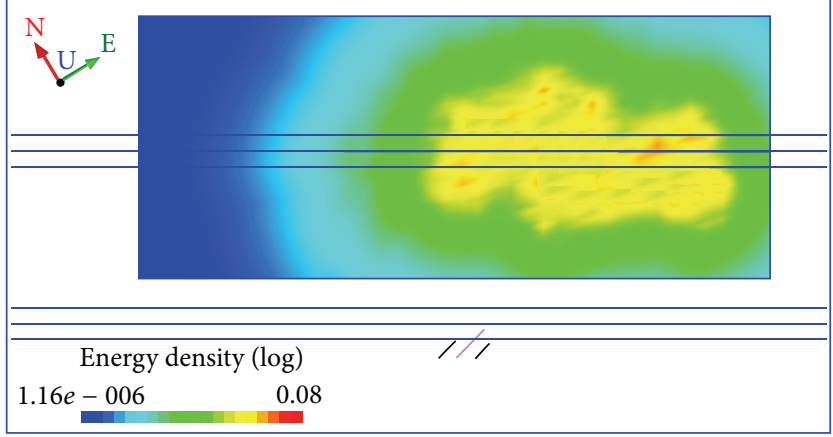

(a)

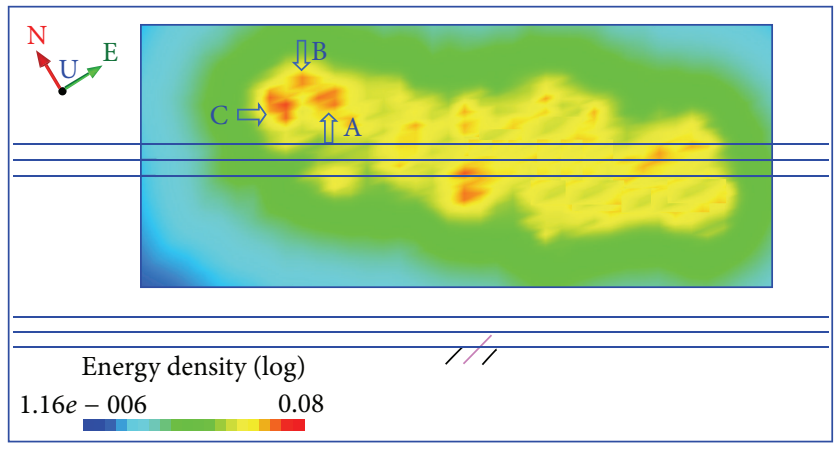

(c)

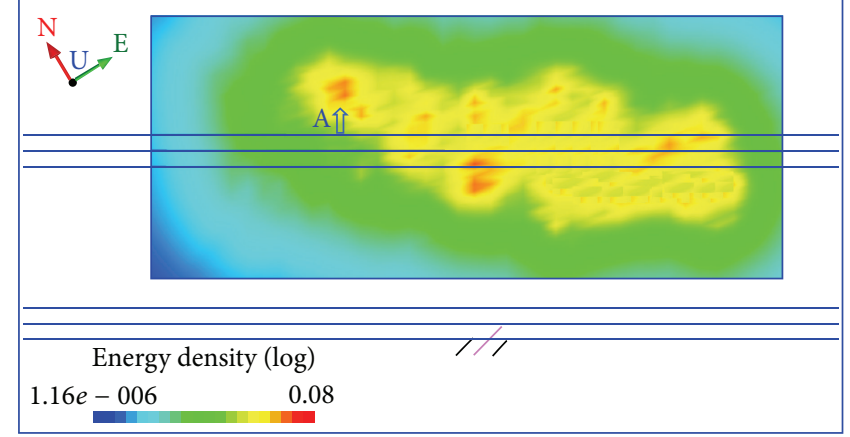

(b)

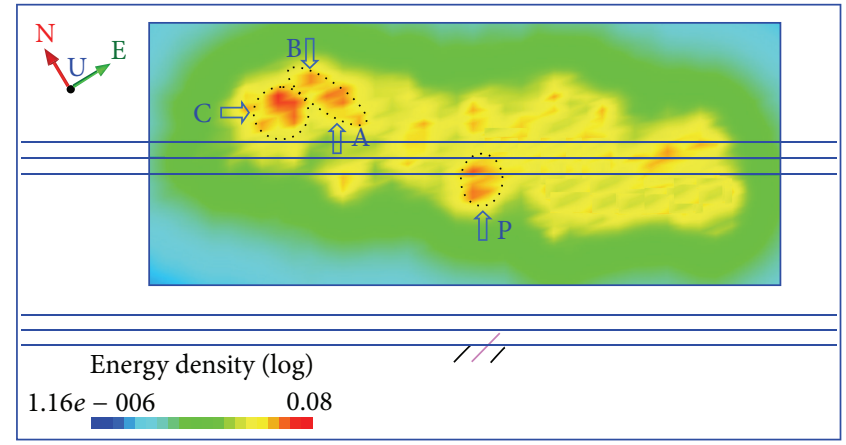

(d)

FIGURE 9: Topographical map of the evolution of microseismic energy density during TBM tunneling in diversion tunnel \#3 (January 20 to February 21, 2011): (a) dissipated energy density cloud map for January 20-February 5, 2011; (b) dissipated energy density cloud map for January 20-February 10, 2011; (c) dissipated energy density cloud map for January 20-February 16, 2011; and (d) dissipated energy density cloud map for January 20-February 21, 2011.

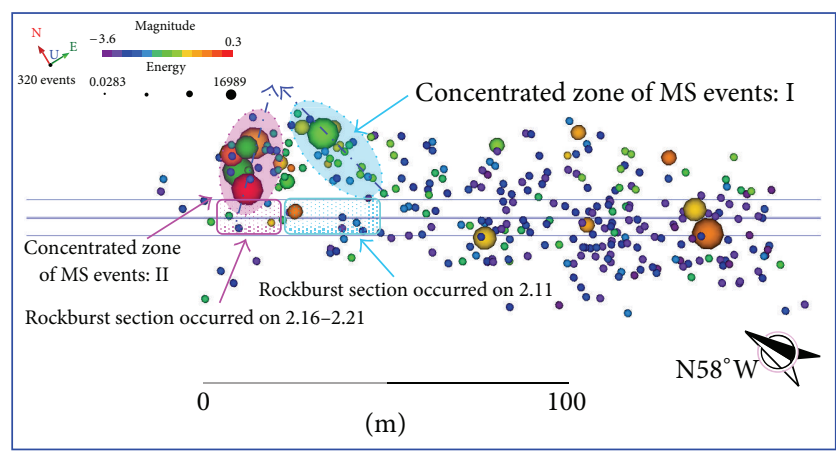

FIGURE 10: Evolution of rockburst nucleation process during TBM tunneling in diversion tunnel \#3 (January 20-March 1, 2011).

$0.3 \mathrm{~m}$, and the greatest ejection distance was $3.5 \mathrm{~m}$. Numerous bulky stones fell from the vault. The TBM cutter head was stuck, and the support systems suffered severe damage. After the strong rockburst on February 19, V-shaped craters were observed in the north sidewall to the hance (Figure 11(d)). There were clear scratches on the failure surface, which exhibited a stepped pattern. During the scene survey, a mostly closed NNW trending recessive weak structural plane was noted near the south sidewall.

\section{RFPA Numerical Simulation}

To further effectively verify and discuss the reasonableness of the data associated with failure of the tunnel sidewall, an RFPA2D simulation of the entire unique process of rock instability failure was used to perform a finite element analysis of the V-shaped crater and the failure process caused by rockbursts. The 2D finite element method- (FEM-) based code known as RFPA was developed by Tang and Kaiser et al. $[35,36]$ and is known as the RFPA-FEM method [37]. RFPA offers unique advantages over other numerical simulation software. The RFPA code accounts for heterogeneous material characteristics at microscopic and macroscopic levels. The code can thus determine the spatial distribution of seismic sources (acoustic emissions) during progressive failure of an advancing tunnel that are caused by material heterogeneity and produce nonlinear behavior. The RFPA code can also simulate and reproduce the entire process of rock failure from microscopic damage to macroscopic instability [38].

5.1. Numerical Model. The numerical model is shown in Figure 12: the model size is $150 \mathrm{~m} \times 120 \mathrm{~m}$; the excavation radius $R$ is $6.5 \mathrm{~m}$; number of elements is $600 \times 480=$ 288,000 ; the width of the weak structural plane is $0.25 \mathrm{~m}$; the angle between structural planes and horizontal is $60^{\circ}$; and the shortest distance from the tunnel center to the weak structural plane is $10 \mathrm{~m}$. The model was gradually loaded until 


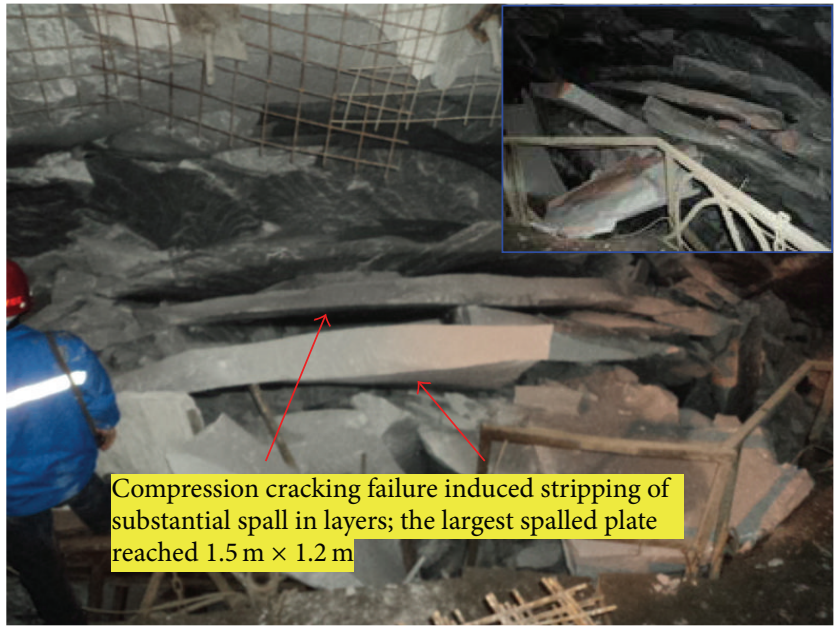

(a)

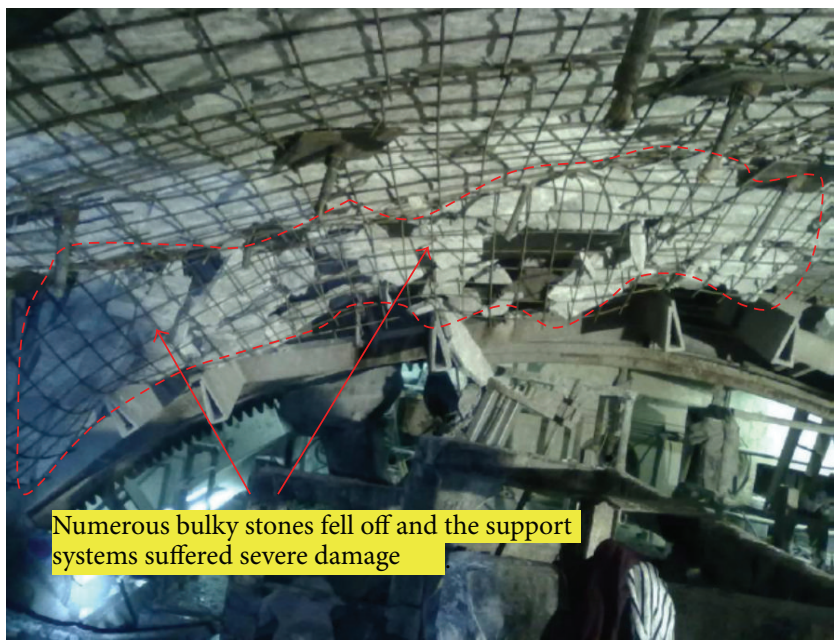

(c)

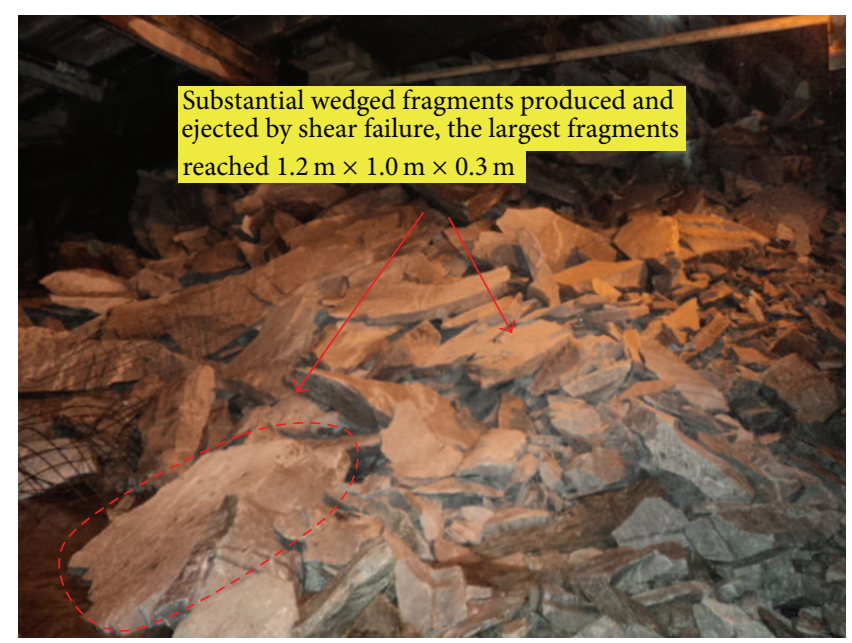

(b)

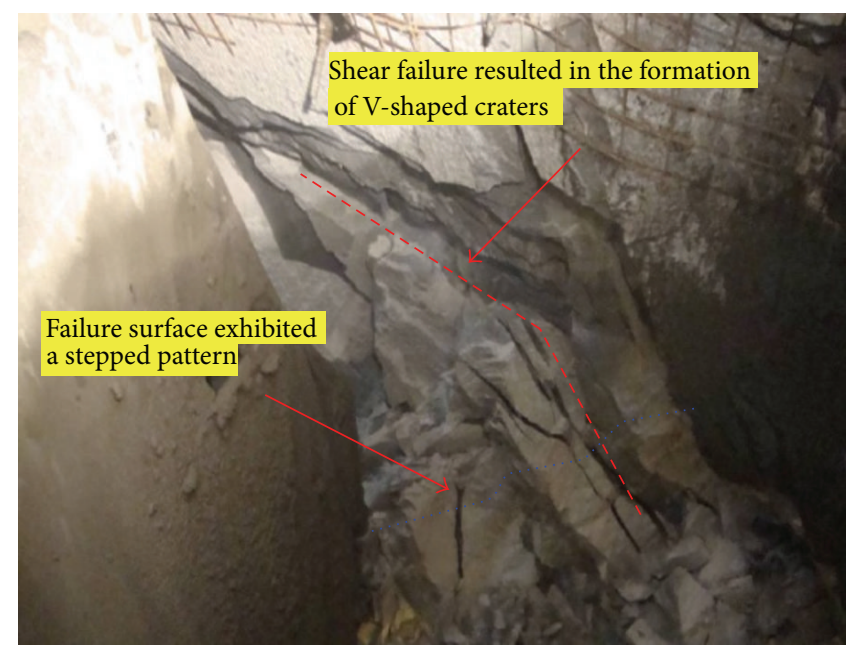

(d)

FIGURE 11: On-site photos showing the failure caused by rockburst. (a) Compression cracking failure induced stripping of substantial spall in layers. (b) Substantial wedged fragments produced by shear failure were ejected to a certain distance. (c) The anchoring-shotcreting and flexible support systems suffered severe damage. (d) Rockburst failure resulted in the formation of V-shaped craters.

$P_{h}$ and $P_{v}$ reached the initial stress level; that is, $P_{h}=32 \mathrm{MPa}$ and $P_{v}=57.6 \mathrm{MPa}\left(P_{h}\right.$ and $P_{v}$ were the initial stresses in the horizontal and vertical directions, resp.), and then the simulated excavation was begun. The measured mechanical parameters of the surrounding rocks and faults are shown in Table 4.

5.2. Analysis of Calculation Results. Figure 13 illustrates the damage evolution of the failure in the rock surrounding the tunnel. Figures 13(a) and 13(b) show the calculated maximum shear stress and the corresponding acoustic emission, respectively. In these figures, the brightness represents the stress level: greater brightness corresponds to greater stress. The red circle denotes tensile failure; the white circle denotes shear failure; the size of the circle represents the energy released from the acoustic emissions; the number of circles represents the quantity of acoustic emissions; and the black area denotes the previously accumulated acoustic emissions.
The plot of the shear stress shows that, in the south and north sidewalls of the tunnel, a superficial stress concentration and cracking occurred first, and the stress distribution was asymmetric. The range of stress adjustment and the local damage zone then expanded, and the stress near the weak structural plane gradually developed from the initial sidewall to the spandrel. The stresses from both the south and north sides were transferred deep into the rock, where the side near the weak structural plane contained a greater stress concentration and a greater range of damage than the other side. The asymmetry of the stress distribution on the two sides of the surrounding rock became more pronounced. When the stress in the left sidewall adjusted and transferred to near the weak structural plane, the structural plane blocked the path of stress transfer and acted as a barrier to the redistribution of the stress. Thus, the stress stopped propagating into the deep rock and propagated along the weak structural plane, which ultimately surrounded the tunnel sidewall to form a 
TABLE 2: Daily footage of TBM tunneling in diversion tunnel \#3 (January 20 to March 1, 2011).

\begin{tabular}{|c|c|c|}
\hline Date & Working face/m & Footage/m \\
\hline 1.20 & $\# 3 \mathrm{~K} 9+770$ & 7 \\
\hline 1.21 & $\# 3 \mathrm{~K} 9+767$ & 3 \\
\hline 1.22 & $\# 3 \mathrm{~K} 9+759$ & 8 \\
\hline 1.23 & $\# 3 \mathrm{~K} 9+747$ & 12 \\
\hline 1.24 & $\# 3 \mathrm{~K} 9+735$ & 12 \\
\hline 1.25 & $\# 3 \mathrm{~K} 9+726$ & 9 \\
\hline 1.26 & $\# 3 \mathrm{~K} 9+720$ & 6 \\
\hline 1.27 & $\# 3$ K9 + 715 & 5 \\
\hline 1.28 & $\# 3 \mathrm{~K} 9+715$ & 0 \\
\hline 1.29 & $\# 3 K 9+699$ & 16 \\
\hline 1.30 & $\# 3 K 9+698$ & 1 \\
\hline 1.31 & $\# 3 K 9+686$ & 12 \\
\hline 2.1 & $\# 3 K 9+686$ & 0 \\
\hline 2.2 & $\# 3 K 9+686$ & 0 \\
\hline 2.3 & $\# 3 K 9+686$ & 0 \\
\hline 2.4 & $\# 3 K 9+684$ & 2 \\
\hline 2.5 & $\# 3 K 9+680$ & 4 \\
\hline 2.6 & $\# 3 \mathrm{~K} 9+671$ & 9 \\
\hline 2.7 & $\# 3 K 9+664$ & 7 \\
\hline 2.8 & $\# 3 \mathrm{~K} 9+657$ & 7 \\
\hline 2.9 & $\# 3 K 9+649$ & 8 \\
\hline 2.10 & $\# 3 \mathrm{~K} 9+637$ & 12 \\
\hline 2.11 & $\# 3 \mathrm{~K} 9+630$ & 7 \\
\hline 2.12 & $\# 3 \mathrm{~K} 9+630$ & 0 \\
\hline 2.13 & $\# 3 K 9+630$ & 0 \\
\hline 2.14 & $\# 3 K 9+629$ & 1 \\
\hline 2.15 & $\# 3 K 9+629$ & 0 \\
\hline 2.16 & $\# 3 K 9+623$ & 6 \\
\hline 2.17 & $\# 3 \mathrm{~K} 9+621$ & 2 \\
\hline 2.18 & $\# 3 K 9+619$ & 2 \\
\hline 2.19 & $\# 3 K 9+616$ & 3 \\
\hline 2.20 & $\# 3 K 9+611$ & 5 \\
\hline 2.21 & $\# 3 \mathrm{~K} 9+607$ & 4 \\
\hline 2.22 & $\# 3 \mathrm{~K} 9+607$ & 0 \\
\hline 2.23 & $\# 3 K 9+607$ & 0 \\
\hline 2.24 & $\# 3 \mathrm{~K} 9+607$ & 0 \\
\hline 2.25 & $\# 3 K 9+607$ & 0 \\
\hline 2.26 & $\# 3 \mathrm{~K} 9+607$ & 0 \\
\hline 2.27 & $\# 3 K 9+607$ & 0 \\
\hline 2.28 & $\# 3 K 9+607$ & 0 \\
\hline 3.1 & $\# 3 \mathrm{~K} 9+607$ & 0 \\
\hline
\end{tabular}

pot-shaped structure. The local stress in the right side no longer continued to accumulate and transferred into the deep rock after the stress adjusted to a certain degree.

The plot of the acoustic emissions shows that the superficial areas of the south and north sidewalls were primarily associated with tensile failure during the initial stage of stress adjustment. The first cracks in the rock mass occurred in the two sides of the tunnel wall. Along with the adjustment

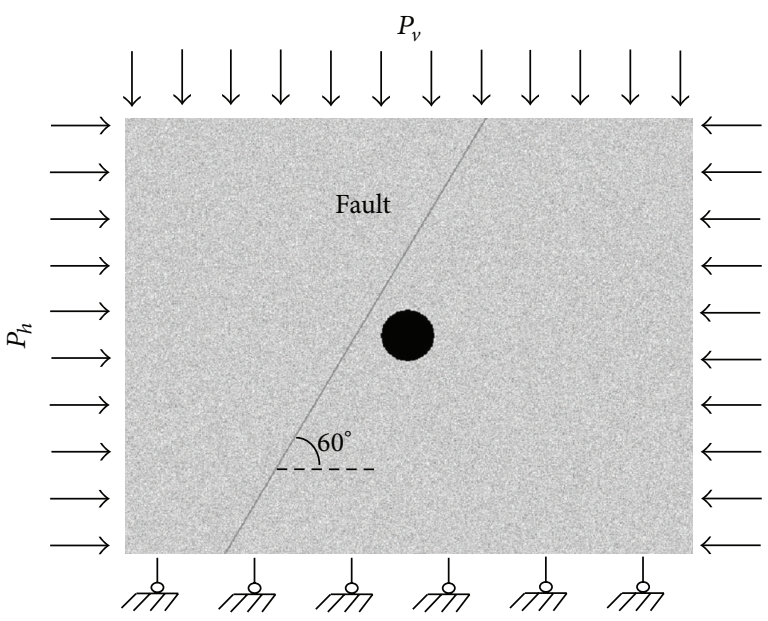

FIGURE 12: Numerical model of the tunnel excavation.

and redistribution of stress, the newly formed tensile cracks continued to propagate deeper, creating a tensile stress concentration in the surrounding rock. The resultant events were dominated by tensile failure. Small cracks coalesced to form larger cracks. New shear cracks formed in the deep rock, resulting in further shear failures. A pot-shaped failure zone first formed near the weak structural plane. Thereafter, the stress adjustment continued on the right side of the weak structural plane. Late in the crack initiation and propagation, the failure mechanism of the rock shifted from the initially dominant tensile failure to shear failure. Ultimately, microcracks developed, coalesced, and formed a $\mathrm{V}$-shaped crater. These results were generally consistent with field observations and the analyzed failure data.

The impact of the inclination of the weak structural plane on the tunnel failure was evaluated for two inclinations: $\alpha=$ $30^{\circ}$ and $45^{\circ}$ (the numerical models are shown in Figure 14). The plot of the shear stress during the tunnel failure shows that, following the tunnel excavation, the stress in both sides of the surrounding rock adjusted and was transferred into the deep rock. The structural plane caused the overall stress field in the side near the weak structural plane to migrate toward the structural plane. However, the weak structural plane hindered the stress transfer, thereby acting as a barrier to redistribution of the stress. Consequently, the surrounding rock between the cavern and the structural plane exhibited a higher stress concentration and was more damaged than that in the side without a structural plane. The plot of the acoustic emissions for $\alpha=30^{\circ}, 45^{\circ}$, and $60^{\circ}$ shows that failure occurred in both sides of the tunnel primarily because the tensile failure in the superficial rock propagated into the deep rock, resulting in a large number of shear failures. When the cracks from the proximal side propagated to the weak structural plane, the rock failure extended and propagated along the structural plane, which ultimately surrounded the cavern wall to form an irregular quadrilateral or V-shaped crater. On the side distal to the structural plane, the tunnel failure primarily resulted in a V-shaped crater. The extent and range of the tunnel sidewall failure increased with greater dips of the structural plane. 
TABLE 3: On-site records of rockburst within the tunnel section of \#3K9 + 770-K9 + 607 .

\begin{tabular}{|c|c|c|c|}
\hline Rockburst time & Rockburst location & Failure modes & Rockburst ranking \\
\hline $2.1103: 30$ & $\# 3 K 9+637-K 9+675$ & $\begin{array}{l}\text { Splitting, stripping of massive spall, and ejection of wedged } \\
\text { stone, with local collapse before rockburst }\end{array}$ & Strong \\
\hline $2.1318: 11$ & $\# 3 \mathrm{~K} 9+651-\mathrm{K} 9+652$ & Stripping scattered fragments & Slight \\
\hline $2.1621: 57$ & $\# 3 \mathrm{~K} 9+623$ & \multirow{3}{*}{$\begin{array}{l}T_{2 b} \text { marble and class III surrounding rocks. Splitting, spalling, } \\
\text { and ejection of massive wedged stone and V-shaped crater. With } \\
\text { a loud noise and local collapse and slight rockburst before } \\
\text { rockburst }\end{array}$} & Intermediate \\
\hline $2.1622: 00$ & $\# 3 K 9+628-K 9+633$ & & Strong \\
\hline $2.1623: 40$ & $\# 3 \mathrm{~K} 9+628-\mathrm{K} 9+635$ & & Strong \\
\hline $2.1814: 50$ & $\# 3$ K9 + 627 & \multirow{2}{*}{ Splitting, spalling, and scattered fragments } & Intermediate \\
\hline $2.1819: 10$ & $\# 3$ K9 + 626 & & Intermediate \\
\hline $2.1915: 42$ & $\# 3 \mathrm{~K} 9+621-\mathrm{K} 9+626$ & $\begin{array}{l}\text { Splitting, spalling, ejection of massive wedged stone, and } \\
\text { V-shaped and pot-shaped cratering }\end{array}$ & Strong \\
\hline \multirow{3}{*}{$2.215: 45$} & $\# 3 \mathrm{~K} 9+607-\mathrm{K} 9+626$, north & \multirow{3}{*}{$\begin{array}{l}\text { Splitting, spalling, and ejection of substantial wedged stone, } \\
\text { with a loud noise and multiple collapse at tunnel working face } \\
\text { rear }\end{array}$} & Strong \\
\hline & $\# 3 \mathrm{~K} 9+613-\mathrm{K} 9+618$, south & & Strong \\
\hline & $\# 3 \mathrm{~K} 9+651-\mathrm{K} 9+664$, south & & Slight \\
\hline
\end{tabular}

TABLE 4: Mechanical parameters used in the numerical model.

\begin{tabular}{lcc}
\hline Parameter & Rock mass & Fault \\
\hline Elastic modulus/(Gpa) & 20 & 2 \\
Uniaxial compressive strength/(Mpa) & 80 & 18 \\
Poisson ratio & 0.26 & 0.32 \\
Homogeneity index & 5 & 3 \\
Friction angle $/\left(^{\circ}\right)$ & 30 & 25 \\
Weight $/\left(\mathrm{N} / \mathrm{m}^{3}\right)$ & 26.2 & 25 \\
\hline
\end{tabular}

\section{Impact of Stress and Energy Transfer on Rockbursts}

On February 21, 2011, three rockbursts occurred simultaneously at 5:45 at different locations along the tunnel axis (Table 2). Among these rockbursts, two strong rockbursts occurred at \#3K9 + 613 to 618 (the south sidewall) and $\# 3 \mathrm{~K} 9+607$ to 626 (the north sidewall), and a small rockburst occurred at \#3K9 + 651 to 664 (the south sidewall). The greatest center-to-center spacing of the rockbursts was $42 \mathrm{~m}$ : thus, the rockbursts occurred at the same time but in different locations. This behavior may be explained as follows. After the rockbursts occurred, the stress field in the underground surrounding rocks was redistributed and partially released, and the remainder of the stress was transferred. Transferred stress will lead to the local stress concentration of rock mass, which may induce rockbursts once again when the accumulated stress reaches a certain level. Therefore, the slight rockburst occurred because of the unloading effect of the early TBM excavation, which created a local stress concentration zone near \#3K9 + 660 (small amount of MS events appeared near \#3K9+660). At this stage, the rock mass was likely in or near a subcritical state before the instability failure. Partial stress was transferred after the strong rockbursts occurred, and the stress tends to transfer toward the region that is under the high-stress status, which further increases a local stress concentration. When the stress reached or exceeded the rock strength, a rockburst may have been triggered simultaneously. During the rockburst, the rock experienced stress accumulation, stress release, and stress transfer (and, correspondingly, energy accumulation, energy release, and energy transfer). This process exactly corresponds to the $3 S$ phenomenon [39] in seismology, that is, stress buildup, stress shadow, and stress transfer.

Therefore, the driving source of rockbursts can be roughly divided into two types: except for the strain energy that accumulates in the local rock mass, the external energy transfer is the driving source for a small proportion of rockbursts; that is, $E_{\text {drive }}=E_{\text {local }}+E_{\text {transfer }}$. The combination of the types may induce a stronger rockburst. Thus, it is critical to stop the occurrence of such rockbursts because a stronger rockburst can induce a new rockburst in the nearby rock. This phenomenon is generally consistent with the conclusion drawn by $\mathrm{Gu}$ et al. [40] in a laboratory rockburst study; in other words, when an ejective rockburst occurs in a project, the accumulated energy of the rockburst itself is insufficient to sustain the failure process, and the surrounding rock must supply or add the required energy.

\section{Conclusions}

(1) In this study, microseismic monitoring was applied to a large-scale deep tunneling project by considering the unique geologic conditions and construction environment of the deep diversion tunnel of the Jinping II Hydropower Station. This monitoring system achieved real-time monitoring and analysis of rock microcracking activity and rockbursts that were caused by unloading from the engineering excavation. The results preliminarily demonstrated the feasibility of applying microseismic monitoring to rockbursts and their prediction in deep tunnels in rock.

(2) The microseismic monitoring information was used in conjunction with on-site accident case studies to clarify the macroscopic instability failure process (including microcrack initiation, propagation, development, and coalescence) in rockburst nucleation and 


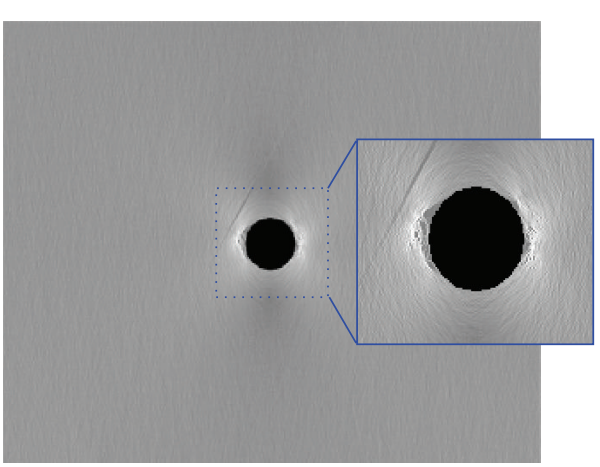

(a1)

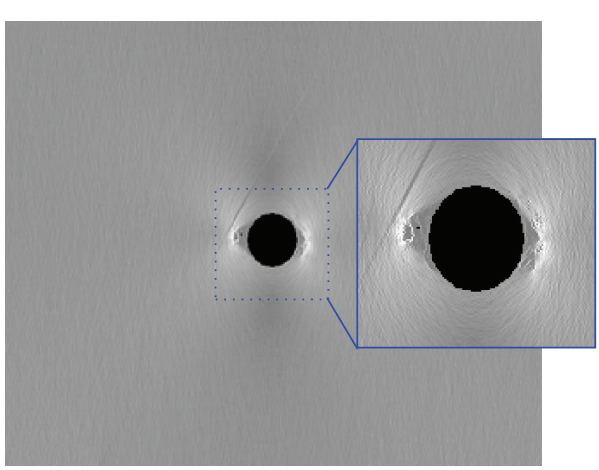

(a2)

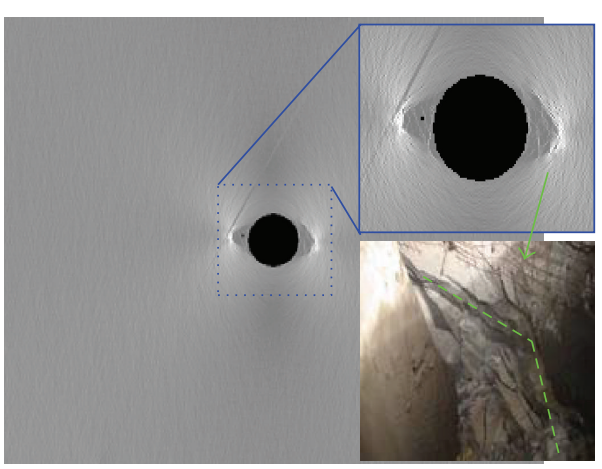

(a3)
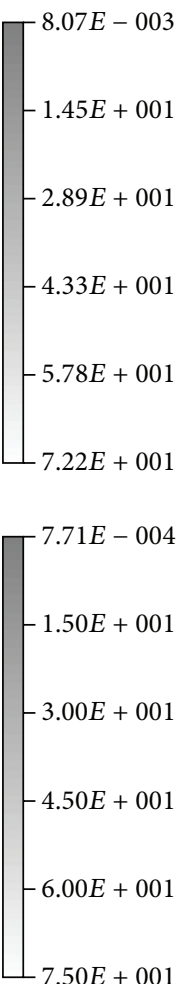

$2.53 E-007$

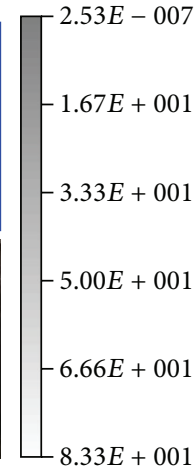

$8.33 E+001$

(a)

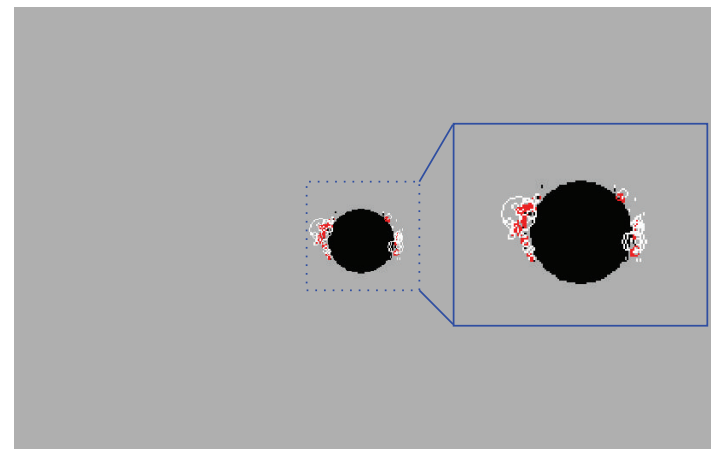

(b1)

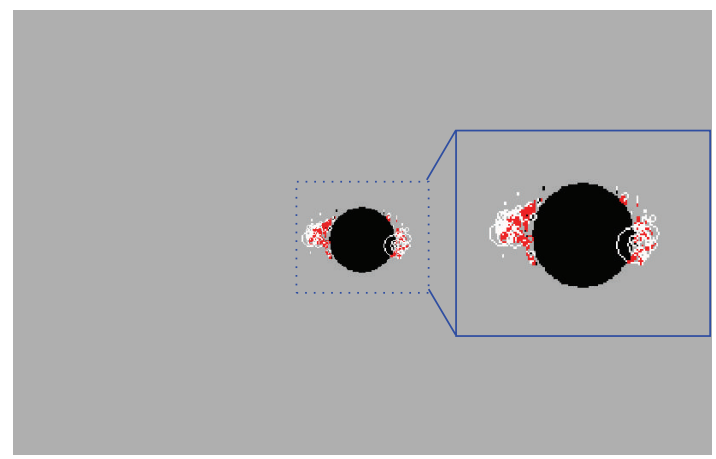

(b2)

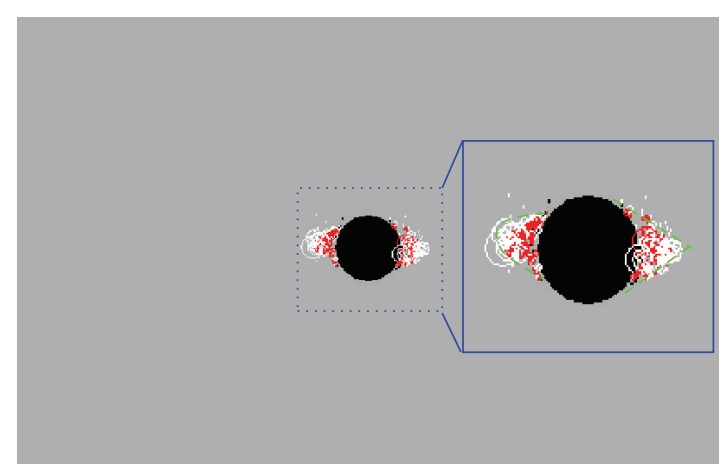

(b3)

(b)

FIGURE 13: Shear stress and acoustic emissions during surrounding rock failure in an underground cavern. (a) Variation in the shear stress during crater formation and (b) acoustic emission distribution during crater formation.

development in terms of dynamic crack propagation. The intrinsic relationship between the spatiotemporal evolution of the microseismicity and the rockbursts was preliminarily explored, and theoretical references were provided for the investigation of rockburst development.

(3) The RFPA finite element program was used to perform a comparative analysis of the crater formation process and the failure modes in underground caverns. The case and simulation results indicated that $\mathrm{V}$ - and pot-shaped craters formed primarily via substantial shear failures that were associated with tensile failure propagation from the superficial rock to the deep rock. The formation and inclination of weak structural planes played a role in controlling the crater formation, and various inclinations can induce different degrees of damage. Based on engineering practice, by integrating the microseismic monitoring and RFPA numerical simulation, the feasibility of rockburst investigation and prediction is expected to be enhanced.

(4) Analysis of a representative on-site rockburst indicated that the driving source of rockbursts may be divided into two types: except for the strain energy that accumulates in the local rock mass, the external energy transfer is the driving source of a small 


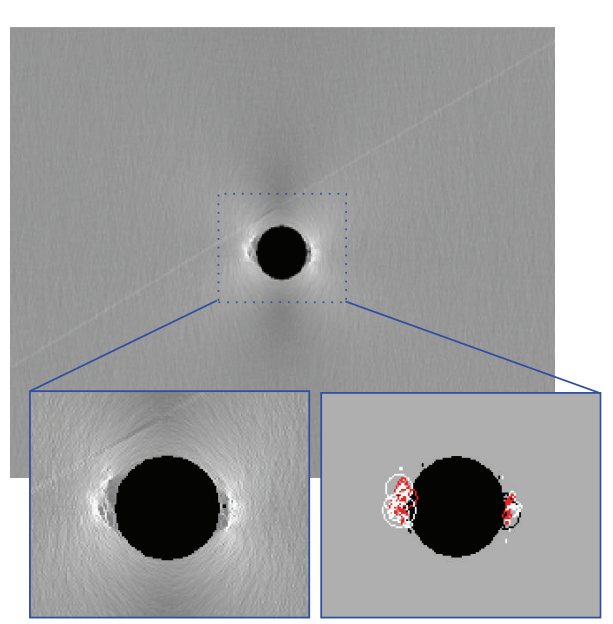

(a1)

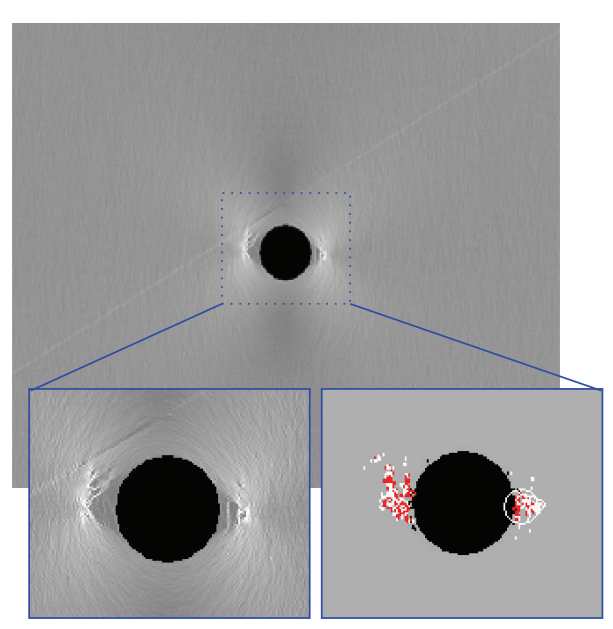

(a2)

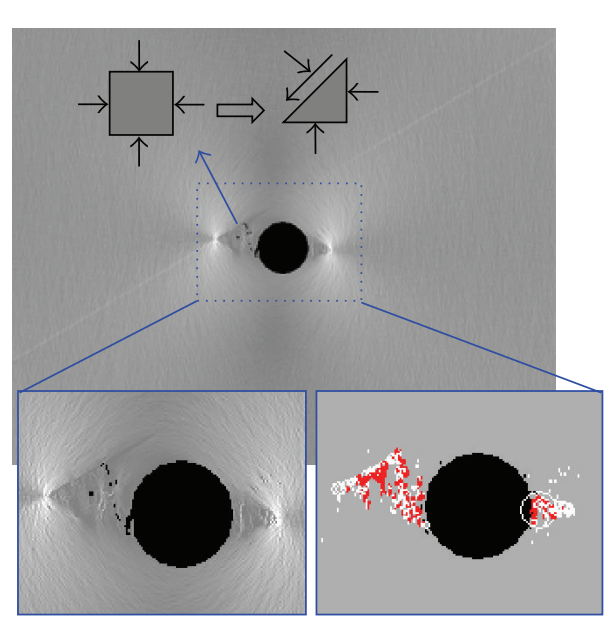

(a3)
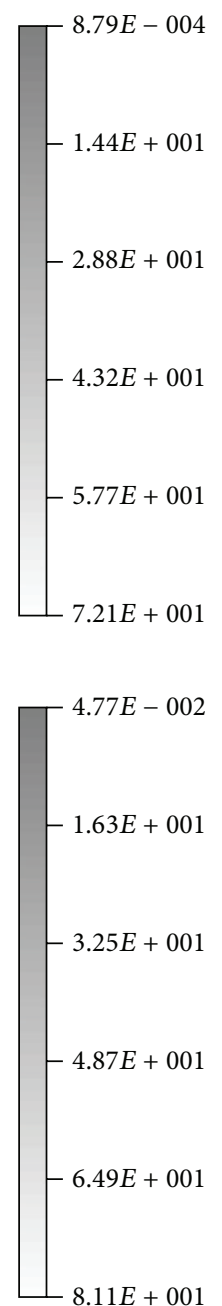

$8.11 E+001$

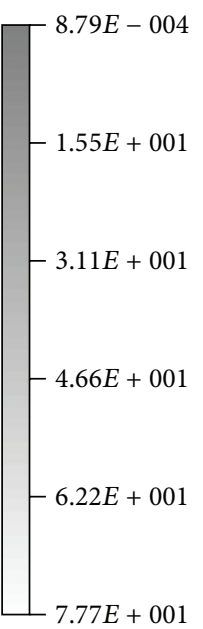

$7.77 E+001$

(a) $\alpha=30^{\circ}$
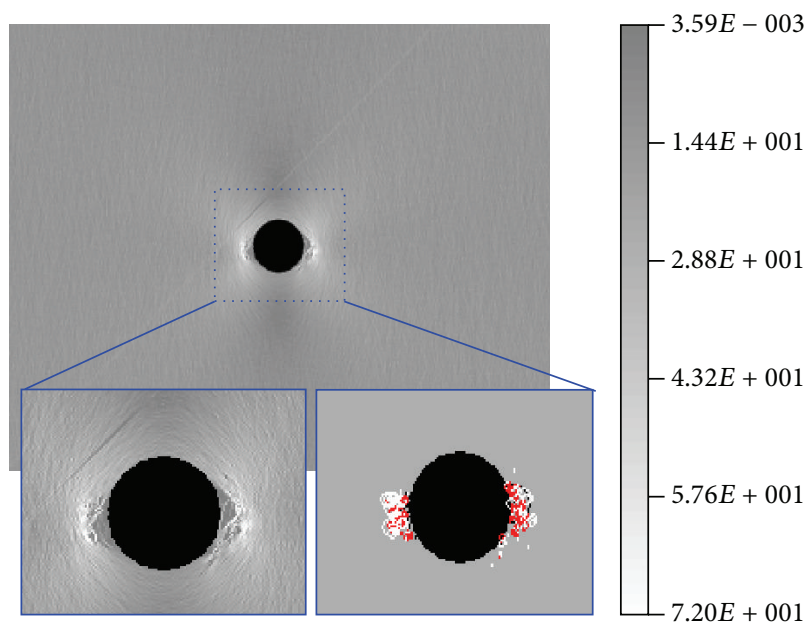

(b1)
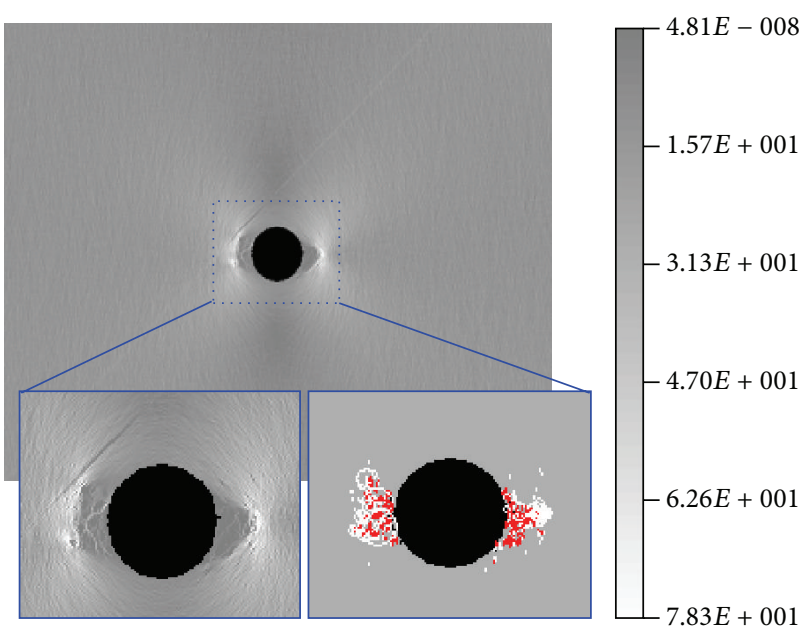

(b2)
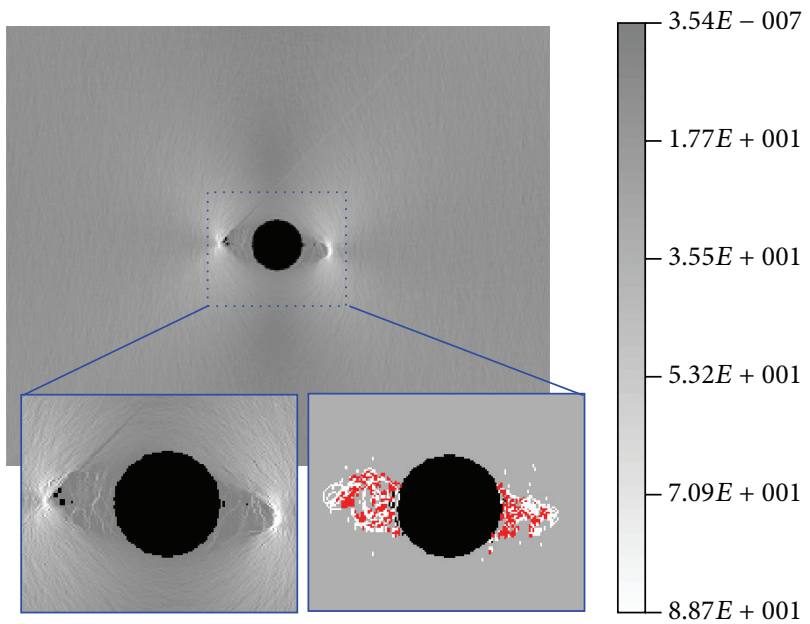

(b3)

(b) $\alpha=45^{\circ}$

FIGURE 14: Shear stress and acoustic emission during surrounding rock failure in an underground cavern for different inclinations $(\alpha)$ of the weak structural plane. (a) Shear stress and acoustic emission distribution during crater formation, $\alpha=30^{\circ}$, and (b) shear stress and acoustic emission distribution during crater formation, $\alpha=45^{\circ}$. 
proportion of rockbursts; that is, $E_{\text {drive }}=E_{\text {local }}+$ $E_{\text {transfer}}$. Strong rockbursts can induce recurrent rockbursts nearby (which are tentatively called triggered rockbursts), in other words, rockbursts that occur at the same time but in different locations.

The causes and mechanisms of rockburst formation are highly complex; thus, the monitoring and prediction of rockbursts has long been a problem in geotechnical engineering worldwide. The application of a microseismic monitoring system for rockburst investigation and forecasting in deep hard-rock tunnels is still at a preliminary stage of exploration and application. Extensive source information can be acquired using advanced monitoring systems, and further study is required to fully exploit and optimize these data to produce reasonable interpretations that can be used to derive rockburst information for prediction and early warning purposes.

\section{Conflict of Interests}

The authors declare that there is no conflict of interests regarding the publication of this paper.

\section{Acknowledgments}

This research work was supported by the National Key Basic Research Development Plan (973) (Grant nos. 2014CB047100, 2011CB013500), the Science Fund for Creative Research Groups of the National Natural Science Foundation of China (Grant no. 51121005), and the Chinese National Natural Science Foundation (Grant nos. 51279024, 41202202, and 51309261).

\section{References}

[1] F. M. Jenkins, T. J. Williams, and C. J. Wideman, "Rock burst mechanism studies at the Lucky Friday Mine," in Proceedings of the 31st US Symposium on Rock Mechanics (USRMS '90), pp. 955-962, A.A. Balkema Publishers, Golden, Colo, USA, June 1990.

[2] R. P. Young, Rockbursts and Seismicity in Mines, A.A. Balkema Publishers, Newfoundland, Canada, 1993.

[3] Y. A. Tan, “The mechanism research of rckburst," Hydrogeology \& Engineering Geology, vol. 1, pp. 34-38, 1989.

[4] R. Guo, C. L. Pan, and R. C. Yu, Theory and Technique of Mining Dealing with Hard Rock Deposits Liable to Rockburst, Metallurgical Industry Press, Beijing, China, 2003.

[5] S. J. Li, X.-T. Feng, Z. H. Li, B. Chen, C. Zhang, and H. Zhou, "In situ monitoring of rockburst nucleation and evolution in the deeply buried tunnels of Jinping II hydropower station," Engineering Geology, vol. 137-138, pp. 85-96, 2012.

[6] E. T. Brown, "Forecast and control on the rockburst," in Foreign Paper Collection on the Rockburst, Department of Science and Technology, Ministry of Water Conservancy and Electric Power, Hydropower Headquarter of Chinese People's Armed Police Force, Beijing, China, 1988.

[7] E. Hoek and E. T. Brown, Underground Excavation in Rock, Institute of Mining and Metallugy, London, UK, 1980.
[8] N. G. W. Cook, "A note on rockbursts considered as a problem of stability," Journal of the Southern African Institute of Mining and Metallurgy, vol. 65, pp. 437-446, 1965.

[9] W. Blake, "Rockburst mechanics," Quarterly of Colorado School of Mines, vol. 67, no. 1, pp. 1-64, 1972.

[10] N. G. W. Cook, E. Hoek, J. P. G. Pretorious, W. D. Ortlepp, and M. D. G. Salamon, "Rock mechanics applied to rockbursts," Journal of the Southern African Institute of Mining and Metallurgy, vol. 66, pp. 435-528, 1966.

[11] Z. T. Bieniawski, H. G. Denkhaus, and U. W. Vogler, "Failure of fractured rock," International Journal of Rock Mechanics and Mining Sciences \& Geomechanics Abstracts, vol. 6, no. 3, pp. 323341, 1969.

[12] C. Krajcinovie and M. A. G. Silva, "Statistical aspects of continuous damage theory," International Journal of Solids and Structures, vol. 18, no. 7, pp. 557-562, 1982.

[13] H. P. Xie, Introduction to Fractal Rock Mechanics, Science Press, Beijing, China, 1996.

[14] M. D. G. Salamon, "Stability, instability and design of pillar workings," International Journal of Rock Mechanics and Mining Sciences and, vol. 7, no. 6, pp. 613-631, 1970.

[15] H. P. Xie and W. G. Pariseau, "Fractal character and mechanism of rockbursts," Chinese Journal of Rock Mechanics and Engineering, vol. 12, no. 1, pp. 28-37, 1993.

[16] Z. Liang, N. Xu, K. Ma, S. Tang, and C. Tang, "Microseismic monitoring and numerical simulation of rock slope failure," International Journal of Distributed Sensor Networks, vol. 2013, Article ID 845191, 10 pages, 2013.

[17] S. J. Gibowicz, "Seismicity induced by mining," Advances in Geophysics, vol. 32, pp. 1-74, 1990.

[18] C. Srinivasan, S. K. Arora, and S. Benady, "Precursory monitoring of impending rockbursts in Kolar gold mines from microseismic emissions at deeper levels," International Journal of Rock Mechanics and Mining Sciences, vol. 36, no. 7, pp. 941948, 1999.

[19] V. A. Mansurov, "Prediction of rockbursts by analysis of induced seismicity data," International Journal of Rock Mechanics and Mining Sciences, vol. 38, no. 6, pp. 893-901, 2001.

[20] R. A. Mercer and W. F. Bawden, "A statistical approach for the integrated analysis of mine-induced seismicity and numerical stress estimates, a case study-part I: developing the relations," International Journal of Rock Mechanics and Mining Sciences, vol. 42, no. 1, pp. 47-72, 2005.

[21] R. A. Mercer and W. F. Bawden, "A statistical approach for the integrated analysis of mine induced seismicity and numerical stress estimates, a case study-part II: evaluation of the relations," International Journal of Rock Mechanics and Mining Sciences, vol. 42, no. 1, pp. 73-94, 2005.

[22] H. P. Xie and W. G. Pariseau, "Fractal character and mechanism of rock bursts," International Journal of Rock Mechanics and Mining Sciences \& Geomechanics Abstracts, vol. 30, no. 4, pp. 343-350, 1993.

[23] L. Z. Tang, Study on monitoring and predietion of seismicity and rockburst in a deep mine [Ph.D. thesis], Central South University, Hunan, China, 2008.

[24] X.-D. Zhao, Y.-H. Li, J.-P. Liu, and J. Tian, "Study on microseismic activity in potential rockburst zone during deep excavation in Hongtoushan mine," Journal of Northeastern University, vol. 30, no. 9, pp. 1330-1333, 2009.

[25] T. I. Urbancic and C.-I. Trifu, "Recent advances in seismic monitoring technology at Canadian mines," Journal of Applied Geophysics, vol. 45, no. 4, pp. 225-237, 2000. 
[26] F. R. P. Basson and S. Van der Merwe, "Seismicity management at hill 50 gold mine," in Deep Mining 07-The Fourth International Seminar on Deep and High Stress Mining, pp. 233-241, Australian Centre for Geomechanics, Perth, Australia, 2007.

[27] A. M. Milev, S. M. Spottiswoode, A. J. Rorke, and G. J. Finnie, "Seismic monitoring of a simulated rock burst on a wall of an underground tunnel," Journal of the South African Institute ofMining and Metallurgy, vol. 101, no. 5, pp. 253-260, 2001.

[28] R. J. Durrheim, A. Haile, M. K. C. Roberts, J. K. Schweitzer, S. M. Spottiswoode, and J. W. Klokow, "Violent failure of a remnant in a deep South African gold mine," Tectonophysics, vol. 289, no. 1-3, pp. 105-116, 1998.

[29] L. Driad-Lebeau, F. Lahaie, M. Al Heib, J. P. Josien, P. Bigarré, and J.-F. Noirel, "Seismic and geotechnical investigations following a rockburst in a complex French mining district," International Journal of Coal Geology, vol. 64, no. 1-2, pp. 6678, 2005.

[30] M. Ge, "Efficient mine microseismic monitoring," International Journal of Coal Geology, vol. 64, no. 1-2, pp. 44-56, 2005.

[31] A. Leśniak and Z. Isakow, "Space-time clustering of seismic events and hazard assessment in the Zabrze-Bielszowice coal mine, Poland," International Journal of Rock Mechanics and Mining Sciences, vol. 46, no. 5, pp. 918-928, 2009.

[32] S. L. Li, "Discussion on microseismic monitoring technology and its application to underground project," Chinese Journal of Underground Space and Engineering, vol. 5, no. 1, pp. 122-128, 2009.

[33] N. W. Xu, C. A. Tang, L. C. Li et al., "Microseismic monitoring and stability analysis of the left bank slope in Jinping first stage hydropower station in southwestern China," International Journal of Rock Mechanics and Mining Sciences, vol. 48, no. 6, pp. 950-963, 2011.

[34] K. Tezuka and H. Niitsuma, "Stress estimated using microseismic clusters and its relationship to the fracture system of the Hijiori hot dry rock reservoir," Engineering Geology, vol. 56, no. 1-2, pp. 47-62, 2000.

[35] C. A. Tang and P. K. Kaiser, "Numerical simulation of cumulative damage and seismic energy release during brittle rock failure-part I: fundamentals," International Journal of Rock Mechanics and Mining Sciences, vol. 35, no. 2, pp. 113-121, 1998.

[36] C. A. Tang, H. Liu, P. K. K. Lee, Y. Tsui, and L. G. Tham, "Numerical studies of the influence of microstructure on rock failure in uniaxial compression-part I: effect of heterogeneity," International Journal of Rock Mechanics and Mining Sciences, vol. 37, no. 4, pp. 555-569, 2000.

[37] G. Li and C.-A. Tang, "A statistical meso-damage mechanical method for modeling trans-scale progressive failure process of rock," International Journal of Rock Mechanics and Mining Sciences, vol. 74, pp. 133-150, 2015.

[38] G. Li, Z. Z. Liang, and C. A. Tang, "Morphologic interpretation of rock failure mechanisms under uniaxial compression based on 3D multiscale high-resolution numerical modeling," Rock Mechanics and Rock Engineering, 2014.

[39] C. A. Tang, T. H. Ma, and X. L. Ding, "On stress-forecasting strategy of earthquakes from stress buildup, stress shadow and stress transfer (SSS) based on numerical approach," Earthquake Science, vol. 22, no. 1, pp. 53-62, 2009.

[40] J. Gu, J. Fan, F. Kong, K. Wang, J. Xu, and T. Wang, "Mechanism of ejective rockburst and model testing technology," Chinese Journal of Rock Mechanics and Engineering, vol. 33, no. 6, pp. 1081-1089, 2014. 

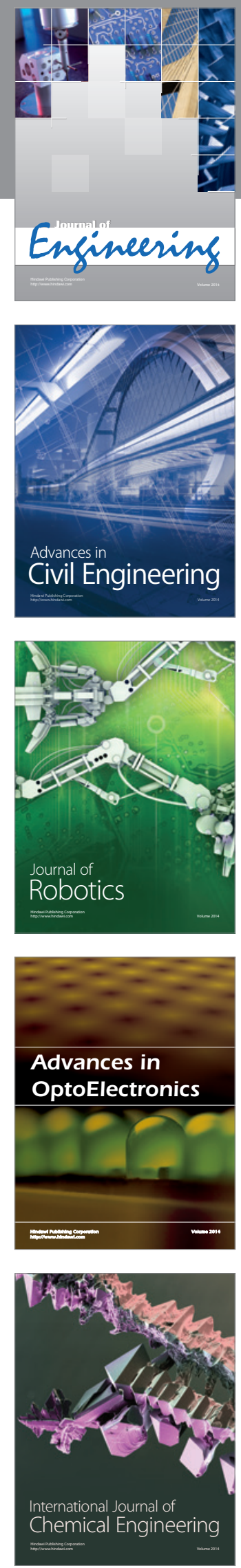

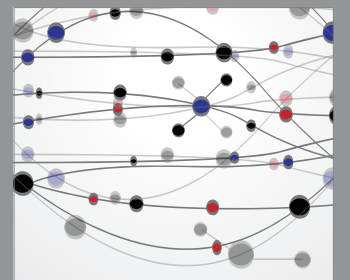

The Scientific World Journal
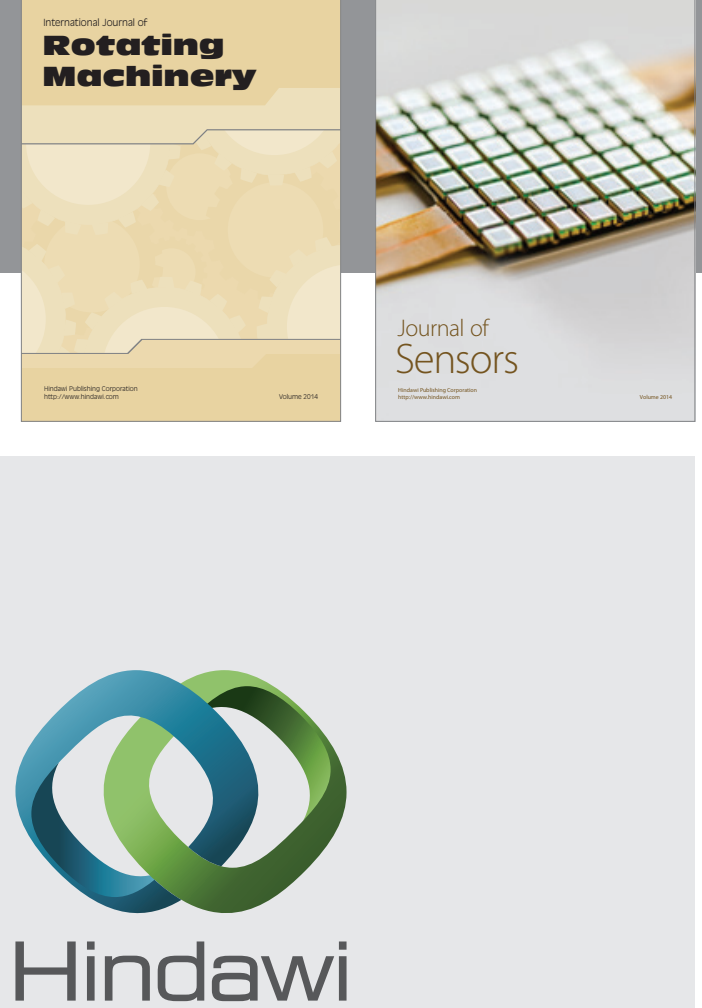

Submit your manuscripts at http://www.hindawi.com
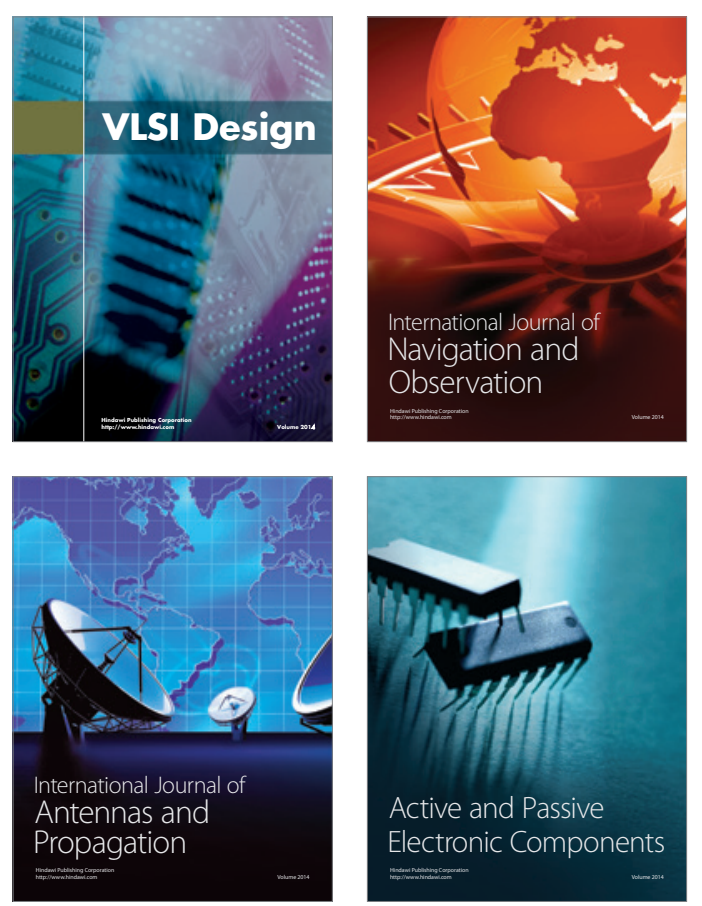
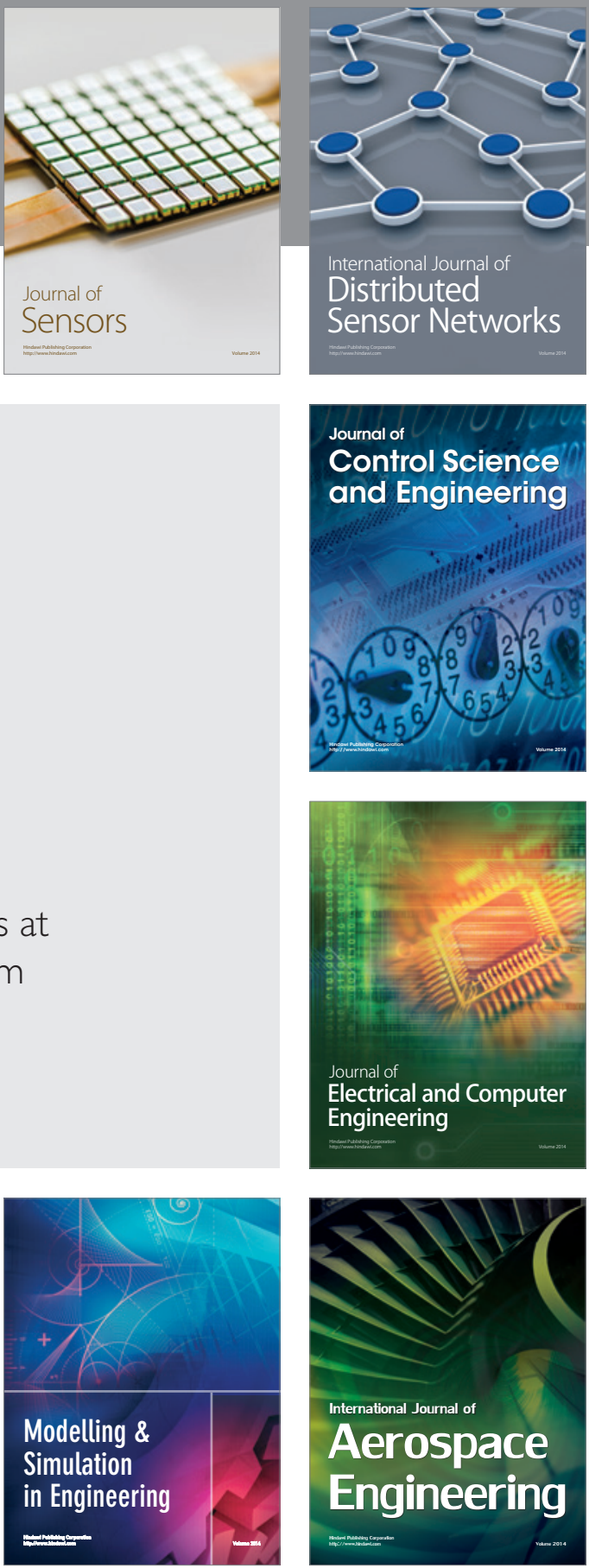

Journal of

Control Science

and Engineering
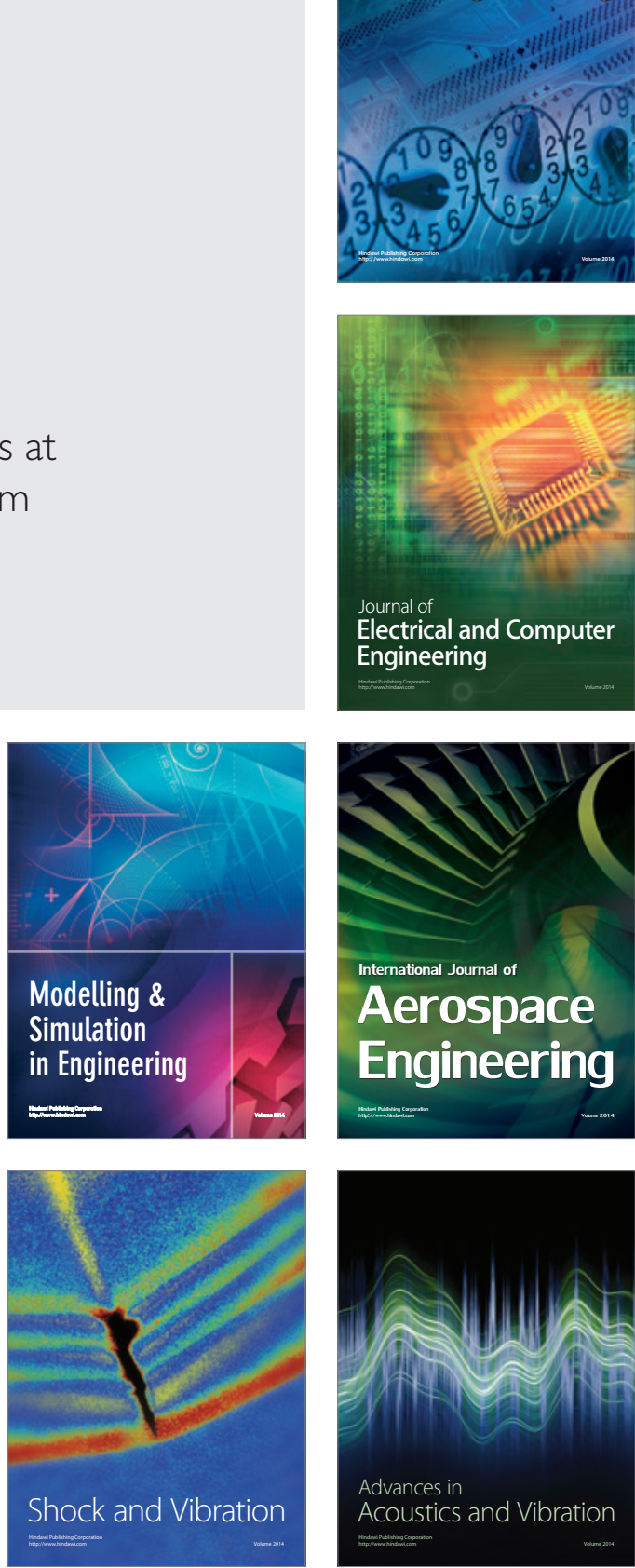